\title{
Low-protein diet applied as part of combination therapy or stand- alone normalizes lifespan and tumor proliferation in a model of intestinal cancer
}

\author{
Alina Proske ${ }^{1}$, Judith Bossen ${ }^{1,2}$, Jakob von Frieling ${ }^{1}$, Thomas Roeder ${ }^{1,2}$ \\ ${ }^{1}$ Department of Molecular Physiology, Zoological Institute, Kiel University, Kiel, Germany \\ ${ }^{2}$ Airway Research Center North (ARCN), German Center for Lung Research (DZL), Kiel, Germany \\ Correspondence to: Thomas Roeder; email: troeder@zoologie.uni-kiel.de \\ Keywords: dietary protein restriction, afatinib, EGFR, Drosophila, stem cells, cancer \\ Received: July 15, $2021 \quad$ Accepted: October 26, $2021 \quad$ Published: November 12, 2021
}

Copyright: (C) 2021 Proske et al. This is an open access article distributed under the terms of the Creative Commons Attribution License (CC BY 3.0), which permits unrestricted use, distribution, and reproduction in any medium, provided the original author and source are credited.

\begin{abstract}
Tumors of the intestinal tract are among the most common tumor diseases in humans, but, like many other tumor entities, show an unsatisfactory prognosis with a need for effective therapies. To test whether nutritional interventions and a combination with a targeted therapy can effectively cure these cancers, we used the fruit fly Drosophila as a model. In this system, we induced tumors by EGFR overexpression in intestinal stem cells. Limiting the amount of protein in the diet restored life span to that of control animals. In combination with a specific EGFR inhibitor, all major tumor-associated phenotypes could be rescued. This form of treatment was also successful in a real treatment scenario, which means when they started after the full tumor phenotype was expressed. In conclusion, reduced protein administration can be a very promising form of adjuvant cancer therapy.
\end{abstract}

\section{INTRODUCTION}

Gastrointestinal (GI) cancers account for about onefourth of the world's cancers as well as more than onethird of all cancer-associated deaths [1,2]. Although there have been substantial advances in the treatment of most forms of GI cancers, the prognosis for most patients remains unacceptably poor. This situation is unlikely to improve in the coming years for most GI cancers, including colorectal cancer (CRC). This negative outlook is based on the premise that risk factors important for the development of CRC, such as cigarette and alcohol consumption and various forms of obesity, continue to increase [3]. These factors, which promote cancer, also include certain food-consumption patterns, including the so-called Western diet, which is particularly rich in fat and carbohydrates [4]. Epidemiological studies show that specific dietary habits significantly reduce the risk of developing cancer $[4,5]$. This finding that different nutritional regimens have a dramatic impact on tumor incidence has caused research to focus on the specific nutritive requirements of tumor cells. Cancer cells require high levels of glucose and growth signals to survive and proliferate, making them particularly vulnerable to nutritional interventions [6]. Consequently, a diet that interferes with the specific metabolic requirements of cancer cells should inhibit tumor growth. One example of such a strategy is interfering with tumor glycolysis; an approach that, for various reasons, is rarely incorporated into therapy [7]. By contrast, another therapeutically relevant form of nutritional intervention, the use of dietary restriction (DR) or caloric restriction (CR), is more promising; DR or CR substantially increases healthspan and lifespan in many model organisms [8-11].

Two types of DR have highlighted the importance of dietary interventions in cancer therapy: a reduction in the amount of protein in the diet and time-restriction of 
food intake. For example, protein reduction in the diet leads to less proliferation in several tumor types $[8,9$, 12]. In addition, a diet that mimics fasting has been successfully used as a supportive treatment in combination with conventional cancer therapy $[13,14]$. Protein restriction can be achieved in several ways: by reducing the amount of single essential amino acid, by reducing the levels of specific non-essential amino acids, or by reducing the levels of all amino acids [15]. Reducing specific non-essential amino acids may reduce cellular proliferation, but cancer cells may adapt accordingly $[16,17]$. A global reduction in amino acid supply results in two major outcomes: 1) a greatly reduced energy intake and 2) a reprogramming of cellular metabolism $[15,17]$. The first outcome might be the reason why therapeutic approaches using this approach have so far remained largely unrealized in clinical practice [18]. Reduced protein intake, on superficial inspection, leads to a condition that is similar to tumor-associated cachexia, which is a common complication in cancer patients that often leads to death [19]. Tumor-associated cachexia is often associated with severe hypermetabolism leading to a negative energy balance and consequently to weight loss mostly affecting muscle mass [19]. Therefore, the energy intake requirement in these patients is increased, which is usually met by energy-rich diets [20, 21]. The lower energy intake that is conferred by DR could, in principle, favor the development of cachexia. However, DR could also counteract the development of cachexia by restoring normal metabolic processes and the corresponding signaling systems that are relevant for metabolic homeostasis [10, 22, 23]. Therefore, the positive influences of DR can far outweigh the negative ones. For this reason, research assessing the potential of dietary interventions in cancer therapy and a better understanding of the underlying processes is urgently needed.

In CRC, like in most other cancers, specific mutations in oncogenes drive tumor progression. Among the most relevant oncogenes in CRC is the epidermal growth factor receptor (EGFR). Together with its downstream targets such as Ras, Raf, or PI3K/Akt, EGFR plays a decisive role in the initiation and development of CRC [24-26]. Moreover, EGFR is overexpressed in 35-49\% of all CRCs [27-29], with overexpression levels of between $25 \%$ and $82 \%$ [30]. EGFR is highly expressed in primary cell cultures of human colorectal carcinomas [31]. As a result, EGFR and downstream signaling molecules are promising targets for directed therapy in CRC.

Animal models that reflect the genetic situation in common human cancers have substantially increased our understanding of how a specific mutation causes tumor development. Besides murine models, the fruit fly Drosophila melanogaster is one of the most important cancer models. As well as enabling quick analysis and a wealth of available genetic tools, Drosophila cancer models allow therapeutic interventions to be assessed not only in terms of the tumor growth but also in terms of lifespan. The ability to measure lifespan - an important benchmark in cancer research - gives Drosophila models a unique advantage over vertebrate models. Importantly, Drosophila is an exceptional model for investigating intestinal cancers, since the majority of the highly conserved mutations associated with human intestinal cancer induce over-proliferation of Drosophila intestinal stem cells (ISCs) and lead to tumor formation [32-34]. Moreover, this system not only reproduces tumor formation but also recaptures cancer-associated phenotypes such as tumor-induced wasting of host organs [35].

In this study, we used Drosophila melanogaster to study the effects of DR (namely, protein restriction), an oncogene-specific pharmacological intervention and DR combined with the pharmacological intervention on tumor development and organismal survival in a stem cell-derived tumor model induced by overexpression of a constitutively active form of EGFR $\left(E g f r{ }^{C A}\right)$. We showed that protein restriction combined with the EGFR inhibitor afatinib reduced tumor growth and normalized life span. By applying these interventions to established tumors, we demonstrated the long-term effectiveness of these interventions.

\section{RESULTS}

The experiments in this study used expression of a constitutively active Egfr allele $\left(E g f r{ }^{C A}\right)$ targeted to ISCs and enteroblasts (esg+ cells) via the binary Ga14/UAS expression system [36]. The TARGET (temporal and regional gene expression targeting) system was used to restrict expression to adults [37]. In this system, concomitant expression of a temperaturesensitive version of the Gal4 repressor Gal80 $\left(\mathrm{Gal} 80^{\text {ts }}\right)$ allows ectopic $E g f r^{C A}$ expression to be induced by increasing the temperature from $18^{\circ} \mathrm{C}$ (restrictive) to $29^{\circ} \mathrm{C}$ (permissive). Crossing to $w^{1118}$ served as control. Upon induction, treatment was immediately applied (later referred to as early application).

\section{DR reduces ISC over-proliferation and normalizes lifespan}

A reduced dietary protein intake (that is, DR) inhibits tumor growth in several tumor models and generally increases lifespan in several types of organisms $[9,10$, $12,38,39]$. We investigated the effects of DR on the over-proliferation phenotype and lifespan in our 
Drosophila model. Animals were fed a modified holidic diet [40] and the ratio of protein to carbohydrate was reduced to $1: 16$. The protein to carbohydrate ratio was $1: 1$ in the control diet. The esg+ cells in the midgut were observed after 5 days and 15 days. There was no difference in the number and shape of esg+ cells in animals on a control diet (5 days old, Figure $1 \mathrm{~A} ; 15$ days old, Figure 1A') and animals on DR (5 days old, Figure 1B; 15 days old, Figure 1B') under control conditions (no induction of the cancer phenotype).
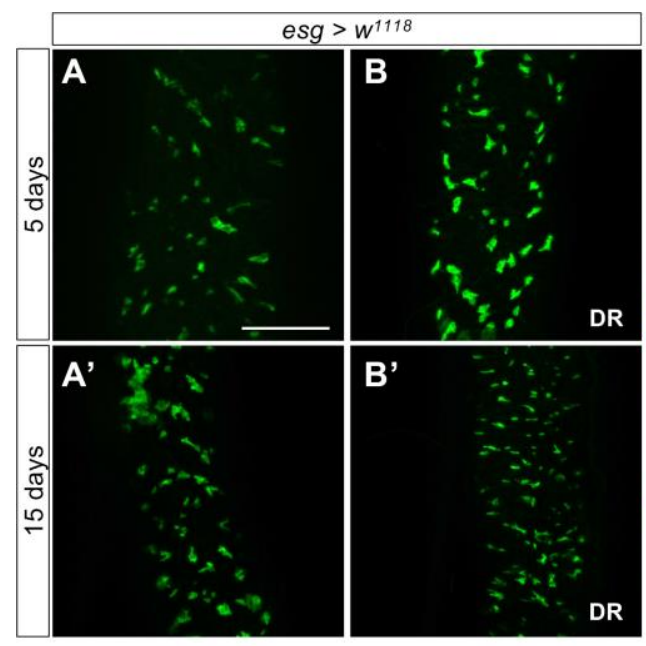
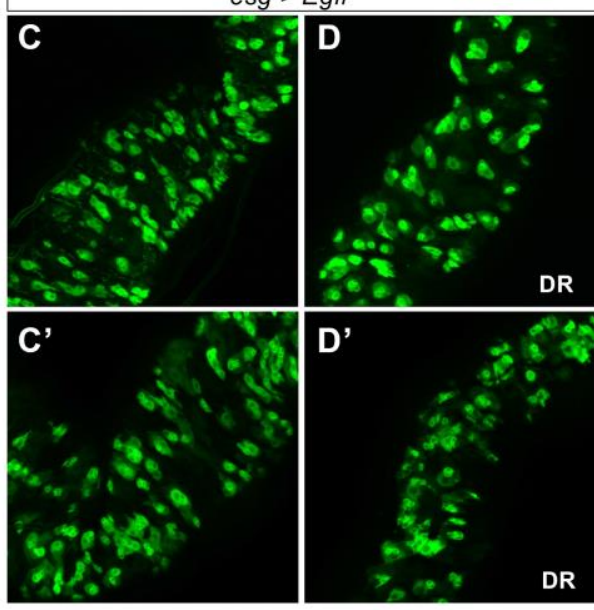

E

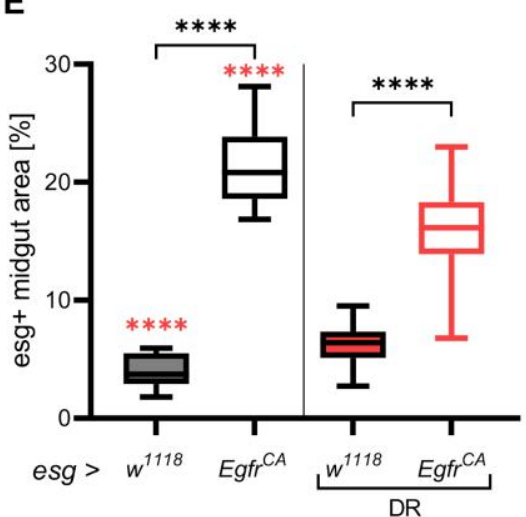

$\mathbf{F}$
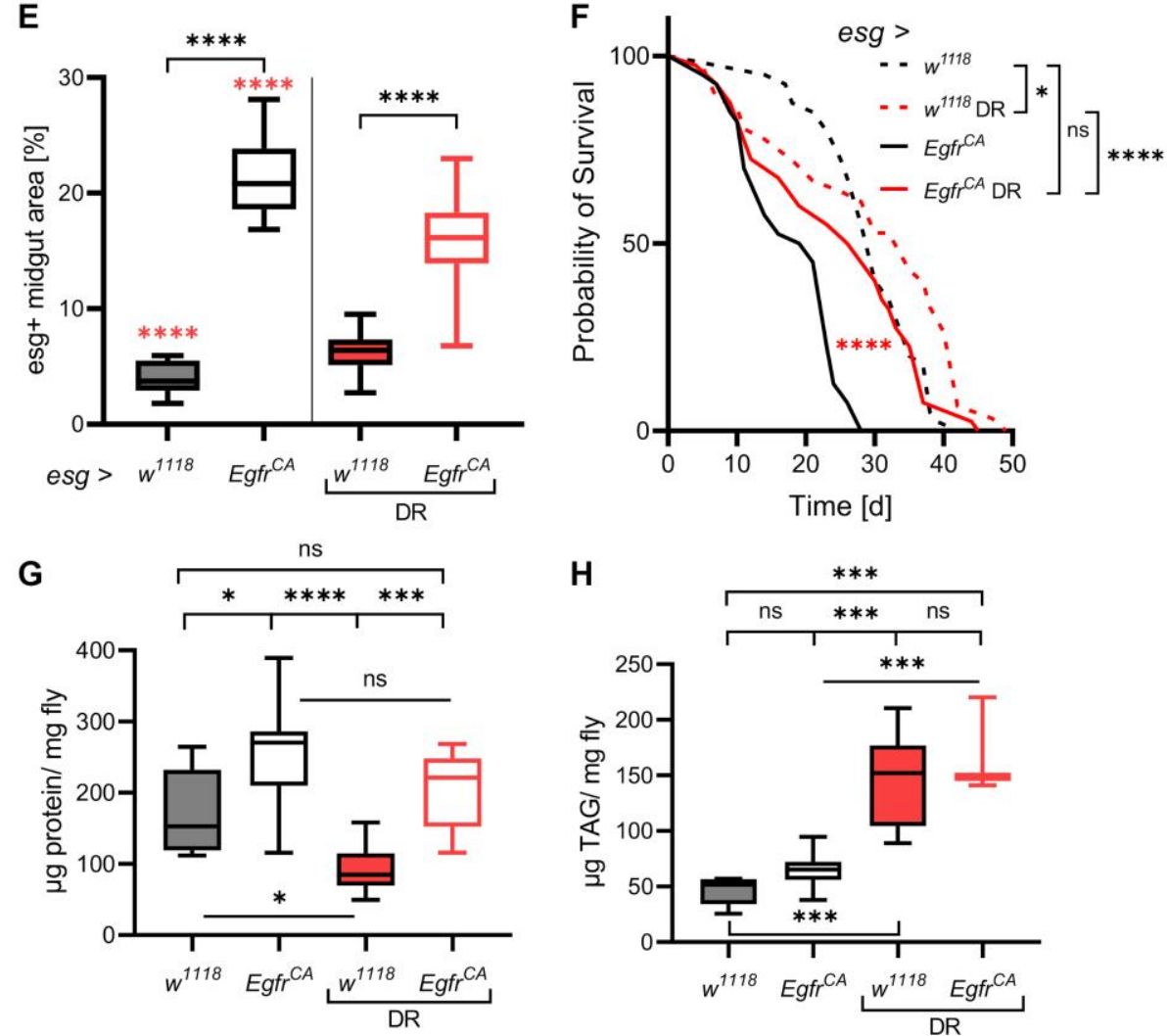

Figure 1. Dietary restriction reduces the $E g f r^{C A}$-induced phenotype. Control animals $\left(e s g>w^{1118}\right)$ and animals with $E g f r$-induced over-proliferation (esg $>E g f r^{C A}$ ) in intestinal stem cells and enteroblasts (esg+ cells) were exposed to dietary restriction (DR) during induction. The esg+ cells are marked with GFP. (A, B) Intestines of control flies with and without exposure to DR after 5 days and 15 days $\left(\mathbf{A}^{\prime}, \mathbf{B}^{\prime}\right)$. (C, D) Intestines of EgfrCA animals with and without exposure to DR after 5 days and 15 days ( $\left.\mathbf{C}^{\prime}, \mathbf{D}^{\prime}\right)$. (E) Quantification of the area covered by GFP-positive cells indicating the number of esg+ cells in the midgut after 5 days of intervention. $n=10-13$. (F) The lifespan of animals exposed to DR. $n=32-40$. (G) Quantification of protein per mg fly after 5 days. $n=10-11$. (H) Quantification of triacylglyceride (TAG) per mg fly after 5 days. $n=10$. Statistical significance was tested by one-way ANOVA and the Tukey test. The lifespan significance was tested by the log-rank (Mantel-Cox) test. Significances are marked with lines or the corresponding color. ns $=$ not significant, ${ }^{*}=p<0.05,{ }^{* * *}$ $=p<0.001,{ }^{* * * *}=p<0.0001$. Scale bar: $100 \mu \mathrm{m}$. 
Table 1. Summarized median lifespans of applied interventions and situations.

\begin{tabular}{|c|c|c|c|c|}
\hline \multirow{3}{*}{ Group } & \multirow{3}{*}{ Intervention } & \multicolumn{3}{|c|}{ Lifespan } \\
\hline & & \multicolumn{2}{|c|}{ Median } & \multirow{2}{*}{$\begin{array}{c}\text { Maximun } \\
\text { days }\end{array}$} \\
\hline & & days & $\%$ & \\
\hline \multirow{2}{*}{$e s g>w^{1118}$} & - & 30 & 100 & 38.5 \\
\hline & DR (early) & 33 & 110 & 44.5 \\
\hline \multirow{9}{*}{$e s g>E g f r C A$} & - & 20 & 66 & 28 \\
\hline & DR (early) & 27 & 90 & 44 \\
\hline & $100 \mu \mathrm{M}$ Afatinib (early) & 25 & 83 & 32 \\
\hline & $50 \mu \mathrm{M}$ Afatinib (early) & 21 & 70 & 27 \\
\hline & Combination $(100 \mu \mathrm{M})$ (early) & 31 & 103 & 40 \\
\hline & Combination $(50 \mu \mathrm{M})$ (early) & 28 & 93 & 39.5 \\
\hline & Afatinib (late) & 23 & 77 & 28 \\
\hline & DR (late) & 33 & 110 & 38 \\
\hline & Combination $(100 \mu \mathrm{M})$ (late) & 28 & 93 & 38 \\
\hline
\end{tabular}

$\mathrm{DR}=$ dietary restriction; early = treatment from onset on; late = treatment from day 5 on; maximum lifespan: mean survival of the oldest $10 \%$.

Expression of $E g f r^{C A}$ in esg+ cells caused overproliferation and cell dysplasia in intestines (Figure 1C, C') characterized by a visible increase in the number of GFP-positive cells with an abnormal phenotype compared with $w^{1118}$ controls (that is, cells without $E g f r^{C A}$ expression; Figure 1A) that were healthy. The abnormal phenotype was observed in flies that were 5 days old and in flies that were 15 days old (Figure 1C, $\left.1 C^{\prime}\right)$. DR only marginally altered the over-proliferation phenotype (Figure 1D, 1D'). Nevertheless, there was a significantly lower number of esg+ cells in $E g f r{ }^{C A}$ flies on DR than in $E g f r^{C A}$ animals fed a normal diet, confirming that DR alters the over-proliferation phenotype (Figure 1E). Transverse cuts through the abdomen showed that control guts have an epithelial monolayer while those of $E g f r{ }^{C A}$ animals developed an epithelial bilayer with increased numbers and size of esg+ cells upon induction. DR was able to reinstate the epithelial monolayer but only marginally reduced esg+ cell size and number (Supplementary Figure 1). The lifespan of flies expressing $E g f_{r}{ }^{C A}$ was significantly lengthened upon DR and was similar to the lifespan of the $w^{1118}$ control fed a normal diet (Figure 1F). The median lifespan was only slightly reduced to $90 \%$, while the maximum lifespan exceeded controls fed a normal diet (median, $27 \mathrm{~d}$; maximum, $44 \mathrm{~d}$, Table 1). DR increased the median lifespan of $w^{1118}$ significantly (110\%, 33 d; maximum, 44.5 d, Figure 1F, Table 1). To exclude the possibility that DR induced a wasting phenotype, we measured the body composition of protein and fat (Figure $1 \mathrm{G}, 1 \mathrm{H}$ ). Animals expressing $E g f_{r}{ }^{C A}$ had a higher body protein content than $w^{1118}$ controls, regardless of whether animals received a normal diet or underwent DR (Figure 1G, Supplementary Figure 2A).
DR similarly increased the body fat content in both $w^{1118}$ control and $\mathrm{Egfr}^{C A}$ animals (Figure $1 \mathrm{H}$, Supplementary Figure 2B). This result indicates that DR does not induce significant wasting of the animals. Accordingly, DR reduced the number of esg+ cells and prolonged lifespan of $E g f r{ }^{C A}$ animals to a wildtype level.

\section{Afatinib reduces ISC over-proliferation and prolongs lifespan}

To assess the impact of a pharmacological intervention, we treated the animals with a specific EGFR inhibitor. We chose the second-generation EGFR inhibitor afatinib (BIBW2992), which is known to rescue a lethal $E g f r^{C A}$-induced tumor phenotype in Drosophila trachea [41]. Afatinib is an approved treatment for EGFR-positive lung cancers, but it is not yet approved for the treatment of CRC. Microscopic analyses of GFP expression in esg+ cells of the midgut showed that there was no obvious difference in GFP expression between control animals without treatment ( 5 days old, Figure 2A; 15 days old, Figure 2A') and those treated with $100 \mu \mathrm{M}$ afatinib (5 days old, Figure 2B; 15 days old, Figure 2B').

In animals with $E g f r^{C A}$ expression (Figure 2C, 2C'), afatinib reduced the number of GFP-positive cells to a similar number to those seen in $w^{1118}$ controls at 5 days (Figure 2D) and 15 days (Figure 2D'). This was also seen in the transverse cuts, were afatinib was able to reduce the number and size of esg+ cells (Supplementary Figure 1). Quantification of the area covered by GFPpositive cells confirmed that afatinib significantly reduced the number of esg+ cells at 5 days (Figure 2E). 
The lifespan of animals treated with afatinib was significantly longer (median, $25 \mathrm{~d}$; maximum, $32 \mathrm{~d}$ ) than the lifespan of animals that did not receive afatinib (Figure 2F, Table 1; median, $20 \mathrm{~d}$; maximum, $28 \mathrm{~d}$ ), and $w^{1118}$ controls (Figure 2F, Table 1; median, $30 \mathrm{~d}$; maximum, $38.5 \mathrm{~d}$ ). The median lifespan of afatinibtreated animals was $83 \%$ of that of the $w^{1118}$ control, which had a median lifespan of 30 days. In the above experiments, $100 \mu \mathrm{M}$ afatinib was used; a lower concentration of afatinib $(50 \mu \mathrm{M})$ did not rescue the reduced lifespan phenotype of $E g f r^{C A}$-expressing animals (Figure 2F, Table 1). Thus, afatinib reduced the proliferation phenotype and prolonged the lifespan of $E g f r^{C A}$ animals when used at a concentration of $100 \mu \mathrm{M}$.

\section{Additional effects of $D R$ and afatinib on Egfr- induced over-proliferation}

We next investigated if $\mathrm{DR}$ and afatinib reduce the proliferation rate and mitotic activity of the stem cells. To measure the proliferation rate, we stained the intestines with an antibody for phospho-histone $3(\mathrm{pH} 3)$

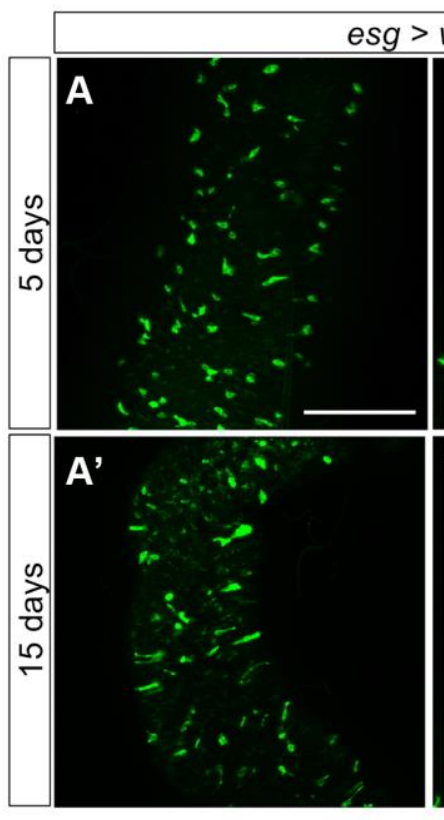

E

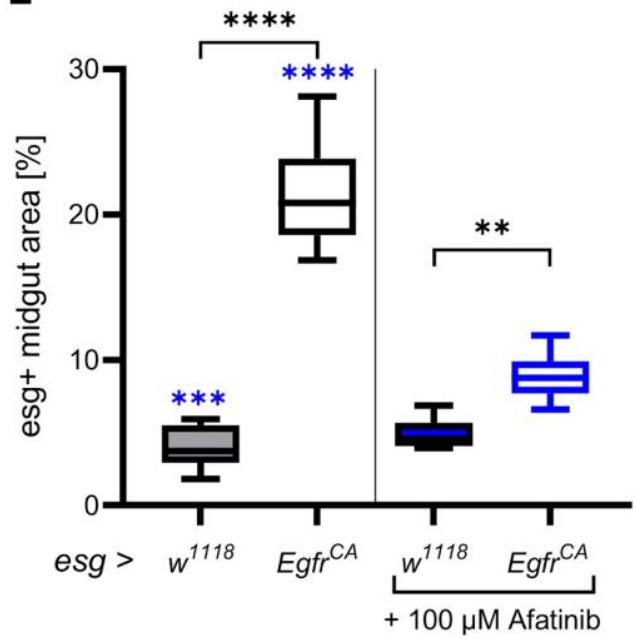

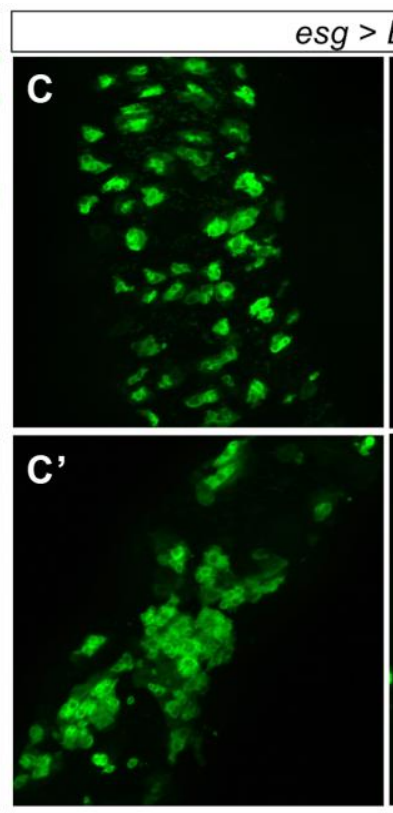

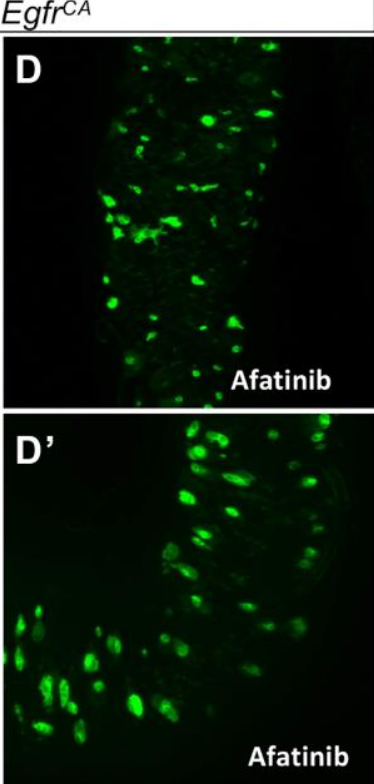

$\mathbf{F}$

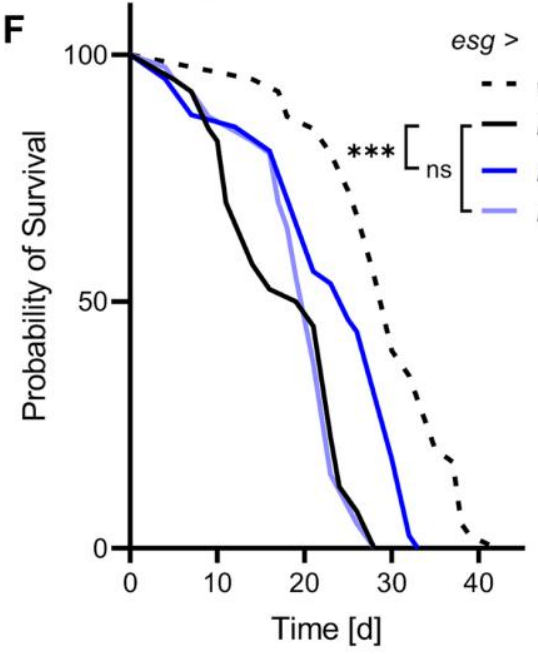

Figure 2. Afatinib reduces the $E g f r^{C A}$-induced phenotype. Control animals (esg $\left.>w^{1118}\right)$ and animals with Egfr-induced overproliferation (esg $>\mathrm{Egfr}^{\mathrm{CA}}$ ) of intestinal stem cells and enteroblasts (esg+ cells) were treated with afatinib (100 $\left.\mu \mathrm{M}\right)$ during induction. The esg+ cells are marked with GFP. (A, B) Intestines of control flies with and without treatment after 5 days and (A', B') 15 days. (C, D) Intestines of $\mathrm{Egfr}^{\mathrm{CA}}$ animals with and without treatment after 5 days and ( $\left.\mathbf{C}^{\prime}, \mathbf{D}^{\prime}\right) 15$ days. (E) Quantification of the area covered by GFPpositive cells in midguts indicating the number of esg+ cells after 5 days of intervention. $n=10-13$. (F) The lifespan of animals treated with $100 \mu \mathrm{M}$ or $50 \mu \mathrm{M}$ afatinib. $n=40$. Statistical significance was tested by one-way ANOVA and the Tukey test. Lifespan significance was tested by the log-rank (Mantel-Cox) test. Significances are marked with lines or corresponding color. ns $=$ not significant, ${ }^{* *}=p<0.01,{ }^{* * *}=p<$ $0.001,{ }^{* * * *}=p<0.0001$. Scale bar: $100 \mu \mathrm{m}$. 
to mark mitotically active cells. The number of mitotically active stem cells was higher in the midguts of Egfr $C A$

A

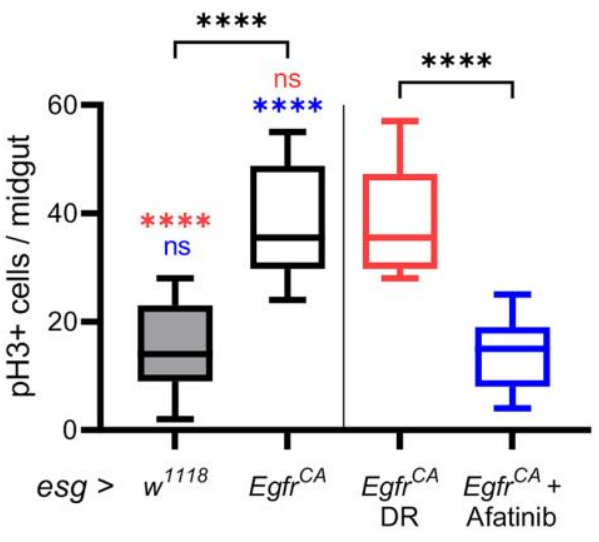

C

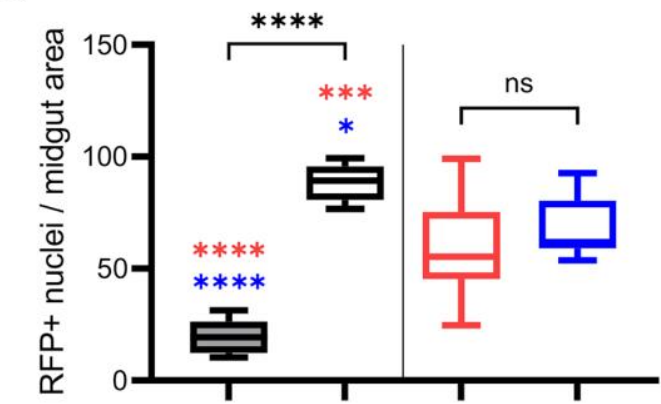

$e^{R e D D M}>w^{1118} \quad E^{R f r}{ }^{C A} \quad \underset{\text { DR }}{E g_{r}^{C A}} \underset{\text { Afatinib }}{E g f C^{C A}}+$

$\mathbf{F}$

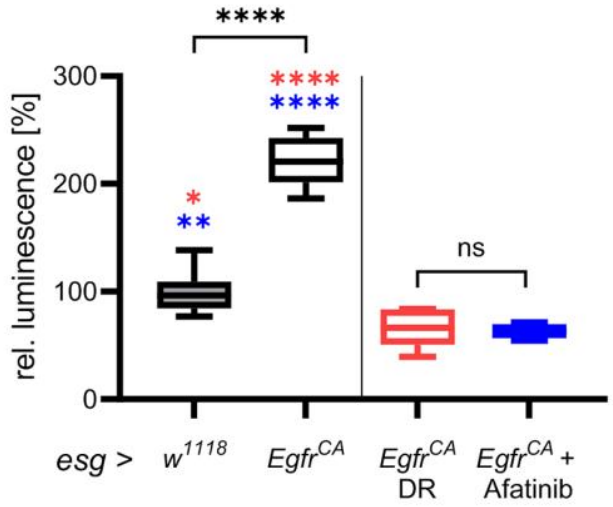

animals than in $w^{1118}$ controls (Figure 3A, 3B, 3B'). There was no difference in the number of $\mathrm{pH} 3$-positive
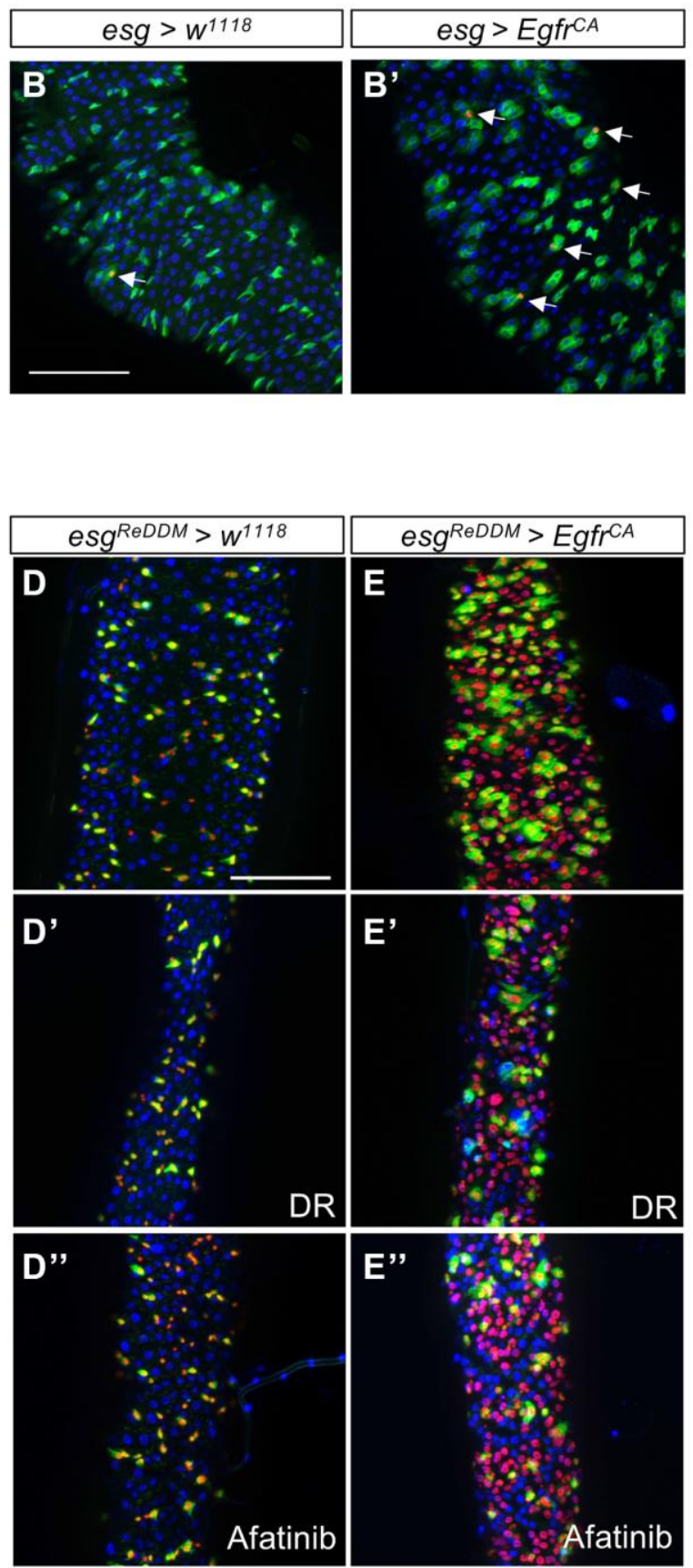

Figure 3. Detailed phenotypic analysis of the effects of DR and afatinib. Control animals (esg $>w^{1118}$ ) and animals with an Egfrinduced over-proliferation ( $\mathrm{esg}>\mathrm{Egfr} \mathrm{C}^{\mathrm{CA}}$ ) of intestinal stem cells and enteroblasts (esg+ cells) were either exposed to dietary restriction (DR) or treated with afatinib at induction. (A) Midguts were stained with an antibody for phospho-histone 3 to mark cells undergoing mitosis after 5 days. Ph3-positive stained cells in the whole intestine were counted. $n=9-11$. (B, $\left.\mathbf{B}^{\prime}\right)$ Midguts of control animals $\left(e s g>w^{1118}\right)$ and animals with Egfr-induced over-proliferation (esg > EgfrCA); esg+ cells are marked with GFP and mitotically active cells are stained red with an anti-pH3 antibody (indicated by the white arrows). (C) Quantification of cells that are RFP-positive through induction of the ReDDM system after 5 days. $n=10-11$. (D-E) Control animals $\left(e s g^{R e D D M}>w^{1118}\right)$ and animals with an Egfr-induced over-proliferation (esg ReDDM $>$ $E g f r^{C A}$ ) in esg+ cells of the midgut were either exposed to DR at induction ( $\mathbf{D}^{\prime}, \mathbf{E}^{\prime}$ ) or treated with afatinib ( $\left.\mathbf{D}^{\prime \prime}, \mathbf{E}^{\prime \prime}\right)$. Esg+ cells are shown in green, RFP-positive progeny are shown in red, and nuclei are shown with blue DAPI staining. (F) Luciferase was quantified in whole animals as a measure of the over-proliferation phenotype after 15 days of induction. $n=5-7$. Statistical significance was tested by one-way ANOVA and the Tukey test. Significances are marked with lines or the corresponding color. ns $=$ not significant, ${ }^{*}=p<0.05,{ }^{* *}=p<0.01,{ }^{* * *}=p<$ $0.001,^{* * * *}=p<0.0001$. Scale bar: $100 \mu \mathrm{m}$. 
cells in $E g f r^{C A}$ animals on DR compared with $E g f r^{C A}$ animals on a normal diet (Figure 3A). Afatinib reduced the proliferation of $\mathrm{pH} 3$-positive cells with $E g f r^{C A}$ expression to the level observed in $w^{1118}$ controls (Figure 3A). Furthermore, we used the ReDDM system (repressible dual differential marker), which marks cell components with fluorophores of varying stability, to investigate the cell turnover [42]. Here, we used esg $g^{R e D D M}$ to mark esg+ cells with GFP and RFP. Since GFP has a shorter half-life than RFP, it is exclusively located in the cytoplasm of esg+ progenitor cells like ISC and enteroblasts. Due to its longer half-life, nucleus-located RFP is visible in all nuclei that develop after induction. When ReDDM is used together with the GAL4-UAS [36] and TARGET systems [37], cell turnover can be visualized in a temporal and tissuespecific manner. We quantified the cell turnover by quantifying the amount of RFP-positive cell progeny. The number of RFP+ nuclei in the midguts of $E g f r{ }^{C A}$ animals exposed to DR and afatinib was significantly lower than in untreated $E g f r{ }^{C A}$ animals fed a normal diet (Figure 3C). DR reduced the number of RFP+ nuclei to a greater extent (Figure 3D', 3E') than afatinib (Figure 3D", 3E") compared with the Egfr ${ }^{C A}$ animals without intervention (Figure 3D, 3E). This effect was evident from microscopic images and quantification of these images (Figure 3C-3E). Luciferase expression was used to measure the increase in cell mass in the whole animal after 15 days of intervention. Luciferase activity was higher in the animals with $E g f r{ }^{C A}$ expression in esg+ cells than in controls; this result was in agreement with the phenotype that we observed after quantification of GFP-positive esg+ cells.

In animals exposed to DR or treated with afatinib, luciferase expression was lower in $E g f r^{C A}$-expressing animals than in $w^{1118}$ controls (Figure 3F). In $w^{1118}$ controls, DR significantly reduced luminescence, but $100 \mu \mathrm{M}$ afatinib did not alter luminescence (Supplementary Figure 3). In conclusion, afatinib, but not DR, reverses the Egfr-induced increase in mitotic activity of the stem cells. DR reduces the cell turnover rate more effectively than afatinib.

\section{DR combined with afatinib restores the wild-type phenotype}

Since DR and afatinib showed beneficial (but different) effects on animals with $E g f r^{C A}$ overexpression, we investigated if the combination of DR and afatinib produced superior effects on cellular phenotypes. We compared all previous results with results from combination intervention experiments (Figure 4). Quantification of esg+ cells showed that DR and afatinib reduced cell numbers to levels seen in $w^{1118}$ control animals; this reduction is significantly greater than the effect of either treatment alone (Figure 4A). Combination treatment did not reduce the number of mitotically active stem cells below the number observed with afatinib treatment alone, but the number of mitotically active cells equaled that of the $w^{1118}$ controls (Figure 4B). Further, we quantified the cell turnover by counting the RFP+ cell progeny. We found that combination treatment significantly reduced the number of RFP+ nuclei compared with either DR or afatinib, showing that the combination treatment had a superior effect (Figure 4C). The reduced number of GFPpositive cells and their RFP+ progeny were clearly visible in microscopic images (Figure 4D). Transverse cuts showed that a combination of DR and afatinib was able to combine the effects of both interventions by reinstating the epithelial monolayer and reducing number and size of esg+ cells in the gut (Supplementary Figure 1). When we measured the luciferase activity in whole animals, which is indicative for the amount of esg+ cells, the combination treatment produced similar effects to each single treatment, which were below the activity measured in $w^{1118}$ controls (Figure 4E). In $w^{1118}$ controls, DR combined with $100 \mu \mathrm{M}$ afatinib reduced luminescence to a similar level to that produced by DR alone (Supplementary Figure 3). We also quantified the effect of the combination treatment on lifespan. We observed that combination treatment resulted in a similar lifespan to that seen in animals subjected to DR alone and in untreated $w^{1118}$ controls (Figure 4F). The combination treatment prolonged the median lifespan to $103 \%$ (31 d), which was longer than the median lifespan that resulted from DR alone $(90 \%, 27$ d) (Table 1, Figure 4G).

This result prompted us to investigate if DR also has a positive effect in combination with a lower afatinib concentration. DR combined with $50 \mu \mathrm{M}$ afatinib resulted in the same median lifespan as that produced by DR alone $(93 \%, 28 \mathrm{~d})$. Application of $50 \mu \mathrm{M}$ afatinib alone only marginally increased lifespan (Figure 1F, Table 1).

\section{DR, afatinib, and combination application in a real- life treatment scenario}

The results presented until now are based on the innervations being applied from the point of induction of the over-proliferation onwards. This model measures an early intervention from tumor initiation on, rather than effects on an established tumor. To create a scenario that is more comparable to CRC treatment in patients, we applied the interventions to an established tumor phenotype. We now refer to these two paradigms as early and late application (Figure 5A). Animals with $E g f r r^{C A}$ expression were first induced for 5 days to reach an advanced tumor phenotype. Quantification of the 
A

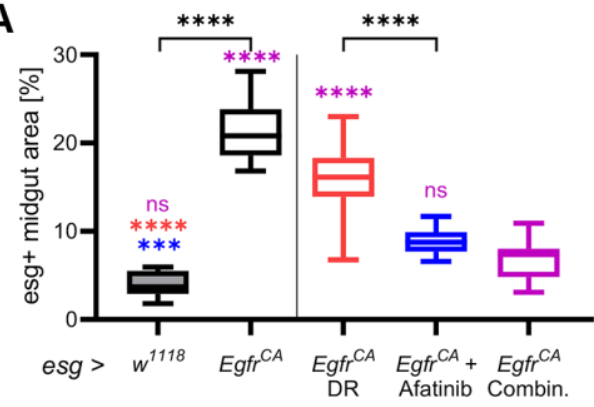

C

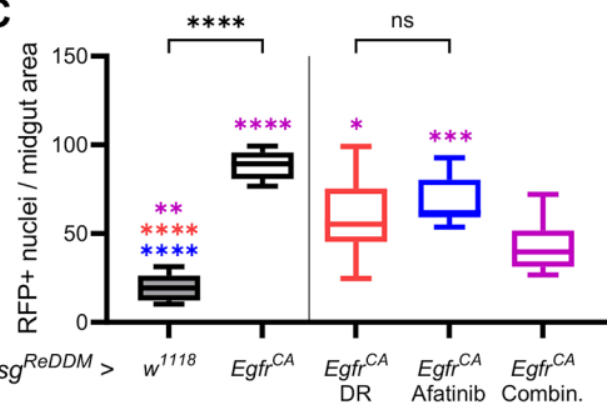

E

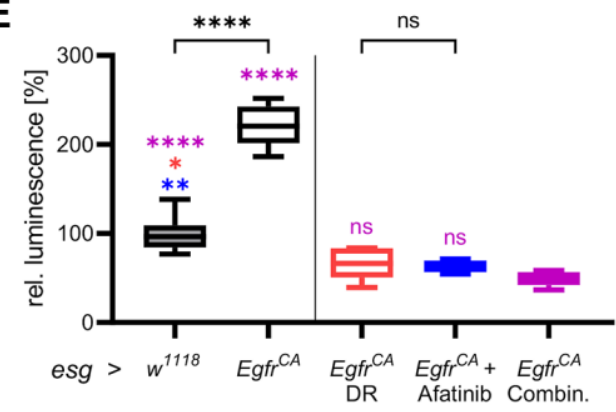

B
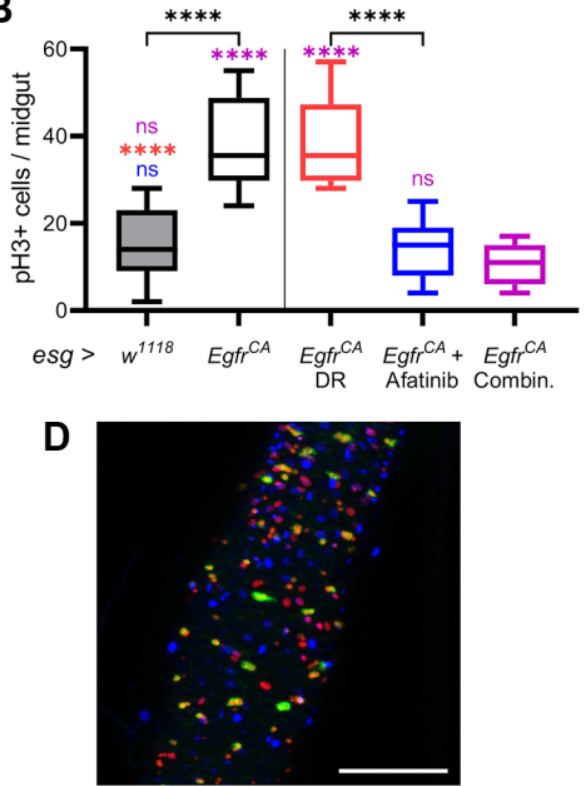

$\mathbf{F}$

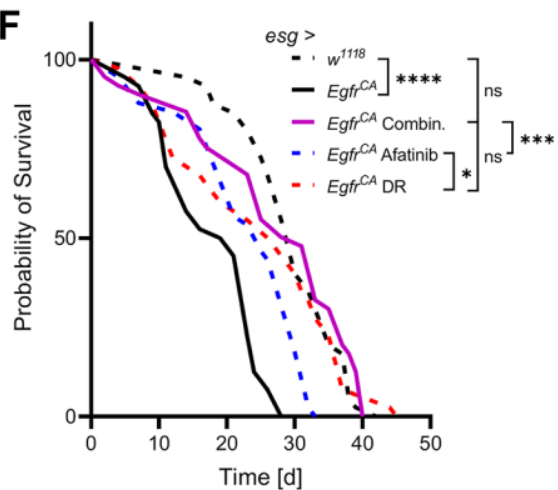

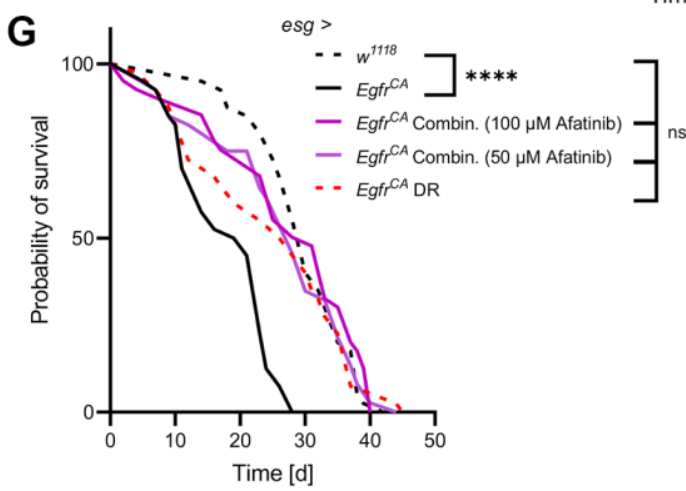

Figure 4. DR combined with afatinib reduces cell proliferation and restores lifespan. Control animals $\left(e s g>w^{1118}\right)$ and animals with Egfr-induced over-proliferation (esg $>E g f r C A$ ) in intestinal stem cells and enteroblasts (esg+ cells) were exposed to a combination of DR and afatinib at induction (shown in magenta). Data were compared to animals that were exposed to dietary restriction (DR, red) or treated with afatinib (blue, $100 \mu \mathrm{M}$ ). (A) Quantification of the area covered by GFP-positive cells indicating the number and size of esg+ cells in the midgut after 5 days of induction. $n=10-13$. (B) Midguts were stained with an antibody for phospho-histone 3 to mark cells undergoing mitosis after 5 days of induction. Positively stained cells in the whole midgut were counted. $n=9-11$. (C) Quantification of cells that are RFP-positive after 5 days of induction of the ReDDM system. $n=10-11$. (D) The combination of both treatments was analysed using the ReDDM system. Esg+ cells are shown in green, RFP-positive progeny are shown in red, and nuclei are shown with blue DAPI staining. (E) Luciferase and GFP were expressed simultaneously and luciferase activity was quantified in whole animals after 15 days of induction. $n=5-$ 7. (F) The lifespan of animals exposed to DR, afatinib, or a combination of DR and $100 \mu \mathrm{M}$ afatinib. $n=32-40$. (G) The lifespan of animals exposed to DR in combination with either $100 \mu \mathrm{M}$ or $50 \mu \mathrm{M}$ afatinib. $n=32-40$. Statistical significance was tested by one-way ANOVA and the Tukey test. Lifespan significance was tested by the log-rank (Mantel-Cox) test. Significances are marked with lines or corresponding color. ns $=$ not significant, ${ }^{*}=p<0.05,{ }^{* *}=p<0.01,{ }^{* * *}=p<0.001,{ }^{* * * *}=p<0.0001$. Scale bar: $100 \mu \mathrm{m}$. 
phenotype and microscopy were performed after 10 consecutive days of treatment. The $E g f r^{C A}$ animals were exposed to DR, treated with afatinib, or exposed to a combination of both; DR and afatinib. We compared the results of these experiments with results obtained from the $w^{1118}$ control, the untreated $E g f r C A$ animals and the early application on day 15 (Figure 5B-5F). Firstly, we quantified the area covered by GFP-positive cells and
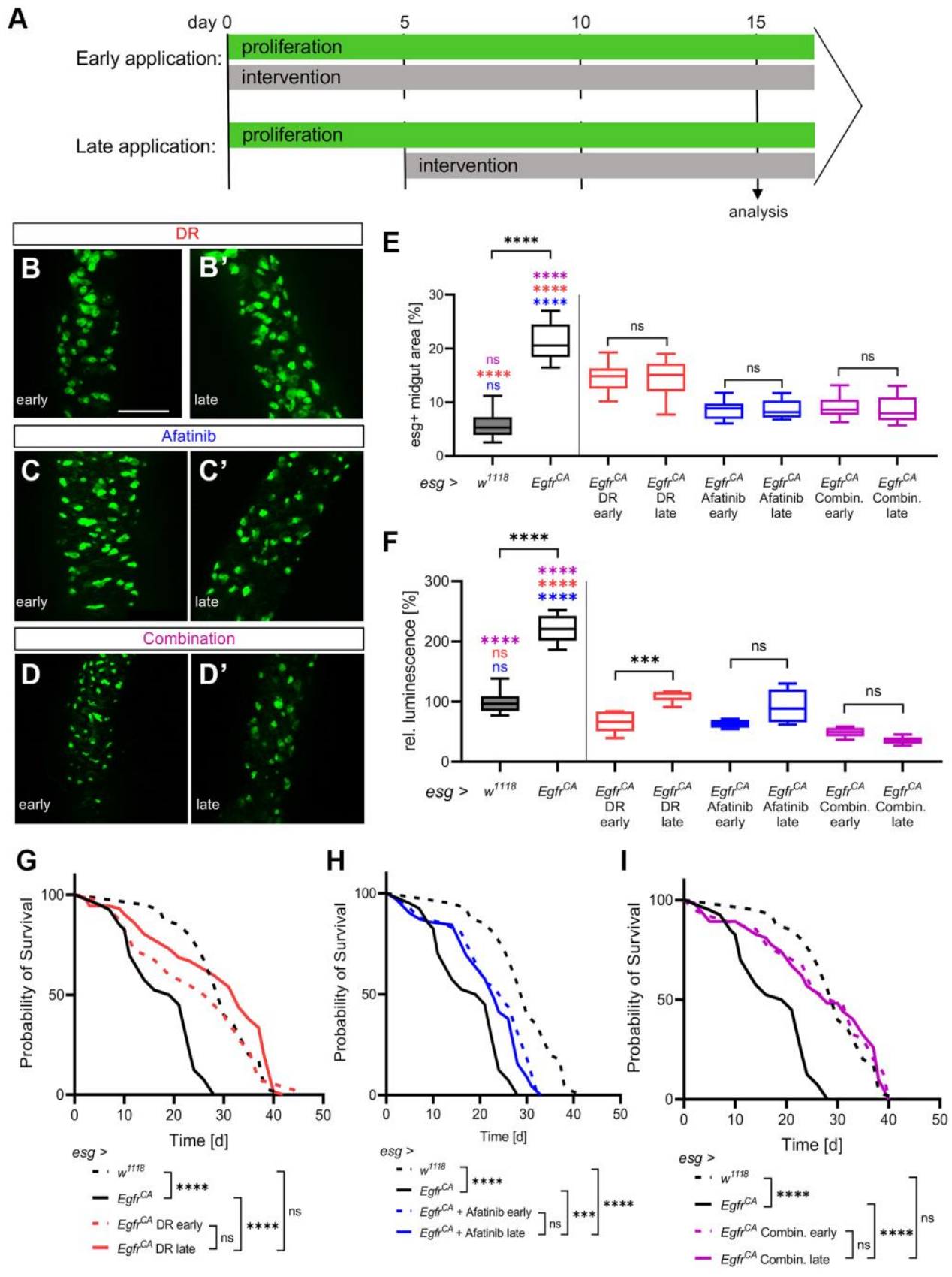

Figure 5. Effects of DR and afatinib on established phenotypes. (A) Control animals (esg $>w^{1118}$ ) and animals with Egfr-induced over-proliferation (esg $>E g f r^{C A}$ ) in intestinal stem cells and enteroblasts (esg+ cells) were given interventions (100 $\mu \mathrm{M}$ afatinib, DR, or a combination of afatinib and DR) either immediately for 15 days (early application, upper row) or 5 days after the onset of over-proliferation for 10 consecutive days (late application, lower row). (B-D) Anterior midguts of animals exposed immediately (early application) to DR, afatinib, or the combination of DR and afatinib. (B'-D') Anterior midguts of animals exposed to DR, afatinib, or a combination of DR and afatinib for 10 days after the onset of over-proliferation to simulate a real-life situation. (E) Quantification of the area covered by GFPpositive cells indicating the number and phenotype of esg+ cells in the midgut. $n=10-12$. (F) Luciferase and GFP were expressed simultaneously and quantified in whole animals to measure the over-proliferation phenotype. $n=5-6$. (G-I) The lifespan of animals exposed to an early application or late application. $n=32-69$. Statistical significance was tested by one-way ANOVA and the Tukey test. The lifespan significance was tested by the log-rank (Mantel-Cox) test. Significances are marked with lines or corresponding color. ns $=$ not significant, ${ }^{* * *}=p<0.001,{ }^{* * * *}=p<0.0001$. Scale bar: $100 \mu \mathrm{m}$. 
esg+ cells in the midgut. There was no difference between the late application and the early application for DR, afatinib, or the combination of DR and afatinib (Figure 5E). Similar observations were obtained from microscopic images (Figure 5B-5D, 5B'-5D'). The effects of afatinib alone or afatinib in combination with DR (but not DR alone) were similar to the effects seen in untreated $w^{1118}$ controls. The approach with late application was used to quantify the number of esg+ cells in the whole animal (as measured by luciferase activity) and these results were compared with those obtained from the early application (Figure 5F). There was no difference between the early and the late application in animals treated with afatinib or afatinib combined with DR. By contrast, DR alone was more effective in reducing the number of esg+ cells in an early situation. The combination of DR and afatinib in a late application reduced the number of esg+ cells to a level below the number observed in $w^{1118}$ controls (Figure 5F). Furthermore, we tested if treatment with $\mathrm{DR}$, afatinib, or a combination of DR and afatinib prolonged the lifespan of animals overexpressing $E g f r{ }^{C A}$. Similar to results obtained in the experiments with early application, each intervention slightly modulated the median lifespan but there was no significant difference between the early and late application. The slight differences observed in median and maximum lifespan are possibly related to the reduced duration of the treatment regime (Figure 5G-5I, Table 1). Thus, the positive effects of DR and afatinib are evident not only upon immediate application, but also with later treatment that more closely resembles the situation that occurs in cancer patients.

\section{DISCUSSION}

Cancer is sensitive to dietary interventions that limit the supply of nutrients [43]. A protein-restricted diet and fasting are associated with a lower cancer risk $[8,44$ 46]. Despite these findings, DR is yet to gain acceptance in clinical practice, which can be attributed to various ambiguities and practical implementation problems. For this reason, we analysed the effects of a well-defined protein reduction diet in an intestinal tumor model and compared the effects of this DR with those of a targeted pharmacological treatment. We found that the combination of a specific pharmacological intervention and protein restriction completely rescued all relevant tumor-associated phenotypes. We performed the project with the fruit fly Drosophila because it offers many advantages; besides the unchallenged wealth of genetic tools, it allows lifespan to be used as the most relevant read-out for both pharmacological and dietary interventions. The effects of DR and CR are well-established in Drosophila, especially the lifespan- and healthspan- prolonging effects [47]. Although the lifespanextending effects of protein restriction are not fully understood, effects on insulin signaling [48] and TOR signaling [47] might not only explain these effects, but also the beneficial effects on tumor growth. Our experiments confirmed that a protein-restricted diet prolongs lifespan. Dietary protein restriction was sufficient to restore the lifespan of animals overexpressing $E g f r^{C A}$ to that seen in control animals. Interestingly, the effects of dietary protein restriction on cellular proliferation were mild. Our findings are in line with other studies showing that a protein-restricted diet reduces tumor growth in human and mouse xenograft models by modulating the IGF/mTOR pathway $[9,12]$. Beyond this, a protein-restricted diet enhances the effects of immunotherapy and causes reprogramming of tumor-associated macrophages [49]. Protein restriction improves insulin and leptin sensitivity in patients with prostate cancer [50]. To avoid complete protein reduction in the diet, some studies depleted intake of dietary methionine, which reduces the growth of KRAS-driven human CRC xenografts in mice both as a preventive and a treatment approach [51]. In a mouse mammary cancer model, methionine reduction decreases proliferation and increases apoptosis [52]. Interestingly, we found no evidence that DR induces a wasting phenotype, both under control conditions and in the cancer model. It remains elusive if this lack of indicators of cachexia is due to our model representing a relatively mild type of intestinal tumors or if this is of general relevance. This has to be taken into account when applied in clinical settings. In obese patients with prostate cancer, restriction of protein intake reduces body mass; however, this outcome was intentional [50]. The depletion of dietary methionine intake during chemotherapy does not affect body mass index and bodyweight in cancer patients [53, 54]. If DR does induce a cachectic phenotype, then a recently developed recurrent DR regimen might be helpful, as it induces the positive effects of DR, while enabling animals to receive a control diet for more than $50 \%$ of the experimental time [48].

One highly interesting result of the current study was the observation that protein restriction combined with a specific pharmacological agent rescued all relevant phenotypes of the cancer model, namely, the overproliferation of intestinal cells and the reduced lifespan. Targeted cancer therapy using highly specific inhibitors is not likely to capture all the relevant components of the complex network of interacting signaling pathways involved in cancer. As such, targeted therapy will probably not rescue all possible disease-associated phenotypes. We used the $E g f^{C A}$ over-proliferation model to mimic EGFR alterations observed in human CRC and treated this model with the specific EGFR 
inhibitor afatinib. Afatinib had beneficial effects on the over-proliferation phenotype in the intestine but was largely ineffective in altering lifespan. Afatinib is an effective standard treatment for NSCLC associated with activating EGFR mutations [55], and it has shown potential in a Drosophila lung tumor model associated with $E g f r^{C A}$ expression [41]. EGFR inhibition is a recommended targeted treatment strategy in CRC [56]. In the current study, afatinib was used as a prototype pharmacological intervention that specifically targets the relevant oncogene. It did not rescue all relevant phenotypes. The high doses of targeted therapies that are needed to obtain their full effectiveness at EGFR might be associated with the development of severe side effects that impair lifespan. Inhibiting several pathways or molecules through combinatorial treatment could be an effective approach for treating complex disease phenotypes. Combinatorial approaches can show additive or even synergistic effects by targeting several proteins in a cancer-signaling network. Except for a study in which methionine restriction was combined with chemotherapy [57], the effectiveness of a protein-restricted diet in combination with a targeted therapy has not been studied sufficiently. By combining afatinib with dietary protein restriction, we brought together the lifespan-prolonging effect of DR with the pharmacologically induced decrease in number of mitotically active cells. This regime could serve as a blueprint for incorporating nutritional interventions into treatment approaches. In addition, the combination of pharmacological and dietary interventions restored the cell turnover rate to that seen in healthy conditions and thereby reduced the growth more efficiently than either afatinib or DR alone. It seems that the protein-restricted diet intervenes in pathways that reduce cell growth and cell division that are not inhibited by afatinib (that is, not the EGFR/MAPK pathway). A possible target for DR is insulin signaling. Combining IGF-1R inhibition with EGFR inhibition turned out to be a possibility in using the EGFR inhibitors gefitinib and osimertinib but not erlotinib [58-60]. These results suggest that combining an EGFR inhibitor with an intervention that reduces insulin signaling is a promising strategy for cancer therapy. Afatinib combined with DR did not alter lifespan to a greater extent than either treatment alone, but with focus on the median lifespan the combination of both turned out to be more effective. An advantage of combining a pharmacological inhibitor with DR is that the toxicity of the drug can be minimized. An increased tolerance to radiotherapy or chemotherapy induced by fasting, energy restriction, or methionine intake restriction prior to the therapy has been repeatedly shown [54, 61-66]. Moreover, a fastinginduced sensitization to radio- and chemotherapy (which has been shown in vitro and in vivo) might account for these positive effects of an additional and accompanying DR [67-70]. In addition, fasting or fasting-mimicking diets enhance the effectivity of combinations of MAPK inhibitors [13, 14].

Taken together our results show that DR, and more precisely a protein-restricted diet, rescues relevant disease phenotypes in a mild intestinal cancer model. Most importantly, DR normalizes lifespan. The full potential of DR can be seen when DR is used in combination with therapeutic strategies, such as EGFR inhibitors, where all relevant tumor-associated phenotypes are rescued. Thus, the inclusion of different forms of DR into cancer treatment strategies is a promising approach that may improve patient outcomes.

\section{CONCLUSIONS}

In the frame of this manuscript, we were able to show that a reduced amount of protein in the ingested diet has a significant positive effect on EGFR-induced intestinal tumors. We used a Drosophila model in which we could precisely adjust the amount of protein in the diet. Protein restriction was shown to have a particularly positive effect on restoring normal life expectancy. In combination with the specific EGFR inhibitor afatinib, all major tumorassociated phenotypes could be normalized. These effects could also be demonstrated in a real treatment scenario where interventions were started after the full tumor phenotype was expressed. The results presented here clearly demonstrate that dietary restriction, in particular the reduction of protein in the diet, shows a positive effect on tumor diseases of the intestine and that, consequently, such intervention strategies should be meaningfully incorporated into therapy regimens.

\section{MATERIALS AND METHODS}

\section{Fly lines and husbandry}

The following fly stocks were used in this study: esgGal4, mCD8::GFP/CyO; H2B::RFP, tub-Gal80ts/TM6 (gift from Tobias Reiff, Düsseldorf), +/+; p\{Esg-gal4\}, p\{UAS-GFP\}, p\{tubulin-Gal80ts\}/p\{Esg-gal4\}, p\{UASGFP\}, p\{tubulin-Gal80ts\}; p\{UAS-Luciferase at attp2 $\} / p\{$ UAS-Luciferase at attp2\} [32], w[1118] (Bloomington Stock Center, \#5905), w[ $\left.{ }^{*}\right] ; P\{w[+m C]=$ Egfr.2.A887T.UAS f8-2 (Bloomington Stock Center, \#9533).

Flies were raised on cornmeal-molasses Drosophila medium at room temperature. Flies were transferred to holidic media for experiments. Afatinib, dissolved in DMSO, was diluted in EtOH before applied to media. Control media were treated with DMSO $(0.1 \%)$. Media for use with afatinib were prepared with low-melt 
agarose instead of agar-agar. $2 \mathrm{ml}$ was aliquoted into each $28 \mathrm{ml}$ Drosophila culture vial.

\section{Media}

A chemically defined holidic diet was used for DR experiments, which was modified after Piper et al. [40]. Restriction of dietary protein intake was attained by reducing the amino acid content of the diet so that the amino acid:carbohydrate ratio was 1:16.

\section{Luciferase quantification}

The luciferase assay was performed using the ONE-Glo luciferase assay system (Promega). Flies were exposed to induction at $29^{\circ} \mathrm{C}$ for 5 or 15 days. Three adult flies per replicate were transferred into $150 \mu \mathrm{L}$ Glo lysis buffer (Promega, \#E2661) and homogenized in a bead homogenizer (OMNI bead ruptor 24, OMNI International) at $3.25 \mathrm{~m} / \mathrm{s}$ for $2 \mathrm{~min}$. After centrifugation at $3000 \times \mathrm{g}$ for $3 \mathrm{~min}, 50 \mu \mathrm{l}$ of the sample was mixed with $50 \mu \mathrm{l}$ of ONEGlo substrate (Promega, \#E6110). Luciferase luminescence was measured with a plate reader (Synergy H1 Plate Reader, Biotek Instruments Inc.,).

\section{Immunohistochemistry and microscopy}

Midguts of flies were dissected in 1x PBS post-induction at $29^{\circ} \mathrm{C}$. Flies that were subjected to the ReDDM system and tissues that were used for cell area measurements were submitted directly to fluorescence microscopy. DNA was stained with DAPI (Roth GmbH, RotiMount Flour-Care DAPI \#HP20.1). Flies that were used in immunohistochemistry experiments were induced for 10 days at $29^{\circ} \mathrm{C}$. The midguts were fixated with $4 \%$ paraformaldehyde for $45 \mathrm{~min}$. The midguts were washed for $3 \times 10 \mathrm{~min}$ in 0.1 PBST (PBS $+0.1 \%$ Triton X-100 (Roth $\mathrm{GmbH}, \# 3051.2$ ) and incubated for $1 \mathrm{~h}$ with blocking buffer (0.1\% PBST $+5 \%$ normal goat serum). Primary antibodies (Cell Signaling technology Inc, pH3 Histone H3 Rabbit AB \#4499; Developmental Studies Hybridoma Bank, DHSB-GFP-8H11-S Mouse AB) were added (1:150 in blocking buffer) and incubated overnight at $4{ }^{\circ} \mathrm{C}$. The midguts were washed $3 \times 10$ min with $0.1 \%$ PBST. Secondary antibodies (Jackson Immuno Research Inc., Alexa Flour 488-conjugated AffiniPure Goat $\alpha$ Mouse IgG \#115-545-205, Cy3-conjugated AffiniPure Goat $\alpha$-Rabbit IgG \#111-165-003) were added (1:300 in blocking buffer) and incubated at $4^{\circ} \mathrm{C}$ overnight. Midguts were washed $3 \times 10 \mathrm{~min}$ with $0.1 \%$ PBST and DAPI (1:2000 in 0.1\% PBST; DAPI \#6843.3, Roth GmbH) was added for $10 \mathrm{~min}$. Tissues were washed once for $10 \mathrm{~min}$ in $0.1 \%$ PBT and mounted on glass slides in $80 \%$ glycerol. Microscopy was performed using a Zeiss Axio imager Z.1 with an apotome and the AxioVision software (Axiovision SE64 Rel.4.9).

\section{Coupled colorimetric assay}

Body fat was quantified using the method of Hildebrandt et al. [71]. Samples for body fat quantification were collected after 5 and 15 days of consecutive induction at $29^{\circ} \mathrm{C}$. Five flies per replicate were collected in screw-cap tubes and the fly weight was assessed. Next, $1 \mathrm{ml}$ of $0.05 \%$ PBST was added before samples were homogenized with a bead homogenizer (OMNI bead ruptor 24, OMNI International) for $2 \mathrm{~min}$ at $3.25 \mathrm{~m} / \mathrm{s}$. Samples of homogenated flies were heated for $5 \mathrm{~min}$ at $70^{\circ} \mathrm{C}$ to inactivate enzymatic activity. Samples were centrifuged for $3 \mathrm{~min}$ at $3000 \times \mathrm{g}$ to separate fly debris and supernatant. To measure body fat, a triglyceride standard was prepared by adding $1 \mu \mathrm{l}$ trioleate (SigmaAldrich, \#T7140) to $455 \mu \mathrm{l} \quad 0.05 \%$ PBST. The triglyceride standard was homogenized and heatinactivated using the same conditions used for sample preparation. The standard was 2-fold diluted with $0.05 \%$ PBST from $100 \mu \mathrm{g} / 50 \mu \mathrm{l}$ to $3.25 \mu \mathrm{g} / 50 \mu \mathrm{l}$. All samples were heated to $37^{\circ} \mathrm{C}$ in a heat block and centrifuged for $3 \mathrm{~min}$ at $2500 \times \mathrm{g}$. Then, $50 \mu \mathrm{l}$ of each sample or standard was pipetted onto a transparent 96well microtiter plate. The absorbance at $500 \mathrm{~nm}$ was measured with a microplate reader (Synergy H1 plate reader, BioTek Instruments Inc.) at T0. Next, $200 \mu \mathrm{l}$ of triglyceride reagent solution (Pointe Scientific, \#T7532500) was added to each well, and the plate was incubated for $30 \mathrm{~min}$ at $37^{\circ} \mathrm{C}$ with mild shaking (200 $\mathrm{rpm})$. The absorbance was measured at $500 \mathrm{~nm}$ to obtain T1 values. The triglyceride equivalent content per fly was calculated using a standard curve.

\section{Bicinchoninic acid assay}

Quantification of body protein content was performed after 5 and 15 days of consecutive induction at $29^{\circ} \mathrm{C}$ by using the same samples used in the coupled calorimetric assay. The protein content of flies was measured with a bicinchoninic acid assay (BCA) using a microplate assay according to the manufacturer's protocol (Pierce BCA protein assay kit \#23227, Thermo Fisher Scientific). For each replicate, $25 \mu \mathrm{l}$ of the sample was pipetted into a transparent 96-well plate, and $200 \mu \mathrm{l}$ of freshly mixed working reagent was added to each well. The plate was shaken for 30 sec to mix the reagents. After incubation at $37^{\circ} \mathrm{C}$ for 30 min, the absorbance was measured with a microplate reader (Synergy H1 plate reader, BioTek Instruments Inc.) at $562 \mathrm{~nm}$.

\section{Analysis of esg+ cell area and RFP-positive nuclei}

Flies were induced for 5 consecutive days at $29^{\circ} \mathrm{C}$ before midguts were dissected. For analysis of esg+ cell 
area, female $\mathrm{F} 1$ progeny of crossings with the esg/GAL4-UAS/GFP-UAS/Luciferase line were used. To quantify RFP-positive nuclei, female F1 progeny of the esg-GAL4 ReDDM line were used. The images for both analyses were obtained with fluorescence microscopy. To exclude observer bias in the quantification of esg+ regions of the midgut, randomly selected (2-3 per replicate) rectangles with an area of $100 \mu \mathrm{m}^{2}$ were placed over different midgut regions. For this purpose, only the DAPI channel was used so that no information about the esg+ signal of this midgut region is available to the observer. For analysis of esg+ area only, the GFP channel of the squares and rectangles were exported as an 8-bit image for analysis in Image $\mathbf{J}$ (version 1.49). To count RFP-positive nuclei, only the DsRed channel of the squares or rectangles was exported. Nuclei were counted with Image J.

\section{Lifespan analysis}

Flies were age-matched and mated. Per replicate, a group of ten female flies was kept on $2 \mathrm{ml}$ of holidic diet in $28 \mathrm{ml}$ vials; vials were maintained at $29^{\circ} \mathrm{C}$. Flies were counted three times per week until all flies had died. Media and vials were changed twice per week minimum.

\section{Vibratome sectioning}

Flies used for vibratome sectioning were kept on $29^{\circ} \mathrm{C}$ for 5 consecutive days upon the respective media and treatment. Flies were decapitated and legs and wings were removed. Posterior abdomen was partly removed with scissors. Thorax and remaining abdomen were pricked with pointed minutien pins. Then animals were submerged in $4 \%$ PFA for $>12 \mathrm{~h}$ at $4^{\circ} \mathrm{C}$ for tissue fixation. Fixated animals were then embedded into 7.5\% agarose. Agarose cubes containing flies were cut in slices with a vibratome (Hyrax V 50, Zeiss) through the transverse plane at a frequency of $80 \mathrm{~Hz}, 0.5 \mathrm{~mm}$ amplitude and $100 \mu \mathrm{m}$ thickness. Slices were incubated with GFP-Booster (1:200 in blocking buffer) overnight at $4{ }^{\circ} \mathrm{C}$. Then slices were washed with $0.1 \%$ PBST for 10 min before being stained with Phalloidin (1:1000 in buffer; Flash Phalloidin ${ }^{\mathrm{TM}}$ Red 594 \#424203, BioLegend) and DAPI (1:200 in blocking buffer; DAPI \#6843.3, Roth $\mathrm{GmbH}$ ) for $10 \mathrm{~min}$. Next, slices were washed again $3 \times 10 \mathrm{~min}$ with $0.1 \%$ PBST before mounted on glass slides for microscopy.

\section{Statistics}

Graph Pad Prism v.7 was used for statistical analysis. Normality was tested with the D'Agostini and Pearson test, or the Shapiro-Wilke test if the sample size was small. One-way ANOVA and the Tukey test were performed for data that conformed to a gaussian distribution. For datasets that included non-gaussiandistributed data, the Kruskal-Wallis test and Dunn's test were performed. The significance of the results of the lifespan assay was calculated with the Mantel-Cox-test. Median-maximum lifespan of the oldest $10 \%$ of flies per group was calculated using Microsoft Excel (Microsoft Office Professional Plus 2016).

\section{AUTHOR CONTRIBUTIONS}

Conceptualization, J.B. and T.R..; methodology, A.P., J.B., J.v.F.; investigation, A.P., J.B., J.v.F; data curation, A.P., J.B., J.v.F; writing-original draft preparation, A.P., J.B., T.R..; writing-review and editing, A.P., J.B., T.R.; funding acquisition, T.R.. All authors have read and agreed to the published version of the manuscript.

\section{ACKNOWLEDGMENTS}

We would like to thank Britta Laubenstein and Christiane Sandberg for excellent technical assistance. We thank the central microscopy facility at the Department of Biology at Kiel University for support with vibratome sectioning. We would also like to thank the Bloomington Stock Center, Tobias Reiff (Düsseldorf, Germany), and Michelle Markstein (Amherst, USA) for flies.

\section{CONFLICTS OF INTEREST}

The authors declare no conflicts of interest related to this study.

\section{FUNDING}

This research was funded by the DFG (CRC 1182, Project C2), the BMBF (Project: DroLuCa2, Alternativen zum Tierexperiment) and supported by the Jürgen Manchot Foundation.

\section{REFERENCES}

1. Ferlay J, Soerjomataram I, Dikshit R, Eser S, Mathers C, Rebelo M, Parkin DM, Forman D, Bray F. Cancer incidence and mortality worldwide: sources, methods and major patterns in GLOBOCAN 2012. Int J Cancer. 2015; 136:E359-86. https://doi.org/10.1002/ijc.29210 PMID:25220842

2. Arnold M, Abnet CC, Neale RE, Vignat J, Giovannucci EL, McGlynn KA, Bray F. Global Burden of 5 Major Types of Gastrointestinal Cancer. Gastroenterology. 2020; 159:335-49.e15. 
https://doi.org/10.1053/i.gastro.2020.02.068 PMID: $\underline{2247694}$

3. Zisman AL, Nickolov A, Brand RE, Gorchow A, Roy HK. Associations between the age at diagnosis and location of colorectal cancer and the use of alcohol and tobacco: implications for screening. Arch Intern Med. 2006; 166:629-34.

https://doi.org/10.1001/archinte.166.6.629 PMID:16567601

4. Steck SE, Murphy EA. Dietary patterns and cancer risk. Nat Rev Cancer. 2020; 20:125-38. https://doi.org/10.1038/s41568-019-0227-4 PMID:31848467

5. Renehan $A G$, Tyson $M$, Egger $M$, Heller RF, Zwahlen $M$. Body-mass index and incidence of cancer: a systematic review and meta-analysis of prospective observational studies. Lancet. 2008; 371:569-78. https://doi.org/10.1016/S0140-6736(08)60269-X PMID: 18280327

6. DeBerardinis RJ, Chandel NS. Fundamentals of cancer metabolism. Sci Adv. 2016; 2:e1600200.

https://doi.org/10.1126/sciadv.1600200 PMID:27386546

7. Ganapathy-Kanniappan S, Geschwind JF. Tumor glycolysis as a target for cancer therapy: progress and prospects. Mol Cancer. 2013; 12:152.

https://doi.org/10.1186/1476-4598-12-152 PMID:24298908

8. Levine ME, Suarez JA, Brandhorst $S$, Balasubramanian P, Cheng CW, Madia F, Fontana L, Mirisola MG, Guevara-Aguirre J, Wan J, Passarino G, Kennedy BK, Wei $\mathrm{M}$, et al. Low protein intake is associated with a major reduction in IGF-1, cancer, and overall mortality in the 65 and younger but not older population. Cell Metab. 2014; 19:407-17.

https://doi.org/10.1016/i.cmet.2014.02.006 PMID:24606898

9. Lamming DW, Cummings NE, Rastelli AL, Gao F, Cava E, Bertozzi B, Spelta F, Pili R, Fontana L. Restriction of dietary protein decreases mTORC1 in tumors and somatic tissues of a tumor-bearing mouse xenograft model. Oncotarget. 2015; 6:31233-40.

https://doi.org/10.18632/oncotarget.5180 PMID:26378060

10. Fontana L, Partridge L. Promoting health and longevity through diet: from model organisms to humans. Cell. 2015; 161:106-18.

https://doi.org/10.1016/i.cell.2015.02.020

PMID:25815989

11. von Frieling J, Roeder T. Factors that affect the translation of dietary restriction into a longer life. IUBMB Life. 2020; 72:814-24. https://doi.org/10.1002/iub.2224

PMID:31889425

12. Fontana L, Adelaiye RM, Rastelli AL, Miles $\mathrm{KM}$, Ciamporcero E, Longo VD, Nguyen H, Vessella R, Pili R. Dietary protein restriction inhibits tumor growth in human xenograft models. Oncotarget. 2013; 4:2451-61. https://doi.org/10.18632/oncotarget.1586 PMID:24353195

13. Caffa I, D'Agostino V, Damonte P, Soncini D, Cea M, Monacelli F, Odetti P, Ballestrero A, Provenzani A, Longo VD, Nencioni A. Fasting potentiates the anticancer activity of tyrosine kinase inhibitors by strengthening MAPK signaling inhibition. Oncotarget. 2015; 6:11820-32. https://doi.org/10.18632/oncotarget.3689 PMID:25909220

14. Lo Re O, Panebianco C, Porto S, Cervi C, Rappa F, Di Biase S, Caraglia M, Pazienza V, Vinciguerra M. Fasting inhibits hepatic stellate cells activation and potentiates anti-cancer activity of Sorafenib in hepatocellular cancer cells. J Cell Physiol. 2018; 233:1202-12.

https://doi.org/10.1002/icp.25987

PMID:28471474

15. Kang JS. Dietary restriction of amino acids for Cancer therapy. Nutr Metab (Lond). 2020; 17:20. https://doi.org/10.1186/s12986-020-00439-x PMID:32190097

16. Lowman $\mathrm{XH}$, Hanse $\mathrm{EA}$, Yang $\mathrm{Y}$, Ishak Gabra MB, Tran TQ, Li H, Kong M. p53 Promotes Cancer Cell Adaptation to Glutamine Deprivation by Upregulating Slc7a3 to Increase Arginine Uptake. Cell Rep. 2019; 26:3051-60.e4. https://doi.org/10.1016/j.celrep.2019.02.037 PMID:30865893

17. Pathria G, Ronai ZA. Harnessing the Co-vulnerabilities of Amino Acid-Restricted Cancers. Cell Metab. 2021; 33:9-20.

https://doi.org/10.1016/i.cmet.2020.12.009 PMID:33406406

18. Fearon KC. Cancer cachexia: developing multimodal therapy for a multidimensional problem. Eur J Cancer. 2008; 44:1124-32. https://doi.org/10.1016/j.ejca.2008.02.033 PMID: 18375115

19. Baracos VE, Martin L, Korc M, Guttridge DC, Fearon $\mathrm{KCH}$. Cancer-associated cachexia. Nat Rev Dis Primers. 2018; 4:17105.

https://doi.org/10.1038/nrdp.2017.105 PMID:29345251

20. Jouinot A, Ulmann G, Vazeille C, Durand JP, Boudou-Rouquette P, Arrondeau J, Tlemsani C, 
Fournel L, Alifano M, Wislez M, Chapron J, Le Bris C, Mansuet-Lupo A, et al. Hypermetabolism is an independent prognostic factor of survival in metastatic non-small cell lung cancer patients. Clin Nutr. 2020; 39:1893-99.

https://doi.org/10.1016/j.clnu.2019.08.003 PMID:31443979

21. Arends J, Bachmann P, Baracos V, Barthelemy N, Bertz $H$, Bozzetti $F$, Fearon $K$, Hütterer $E$, Isenring $E$, Kaasa S, Krznaric Z, Laird B, Larsson M, et al. ESPEN guidelines on nutrition in cancer patients. Clin Nutr. 2017; 36:11-48.

https://doi.org/10.1016/j.clnu.2016.07.015

PMID:27637832

22. Kapahi $P$, Kaeberlein $M$, Hansen $M$. Dietary restriction and lifespan: Lessons from invertebrate models. Ageing Res Rev. 2017; 39:3-14.

https://doi.org/10.1016/i.arr.2016.12.005

PMID:28007498

23. Yu D, Tomasiewicz JL, Yang SE, Miller BR, Wakai MH, Sherman DS, Cummings NE, Baar EL, Brinkman JA, Syed FA, Lamming DW. Calorie-Restriction-Induced Insulin Sensitivity Is Mediated by Adipose mTORC2 and Not Required for Lifespan Extension. Cell Rep. 2019; 29:236-48.e3.

https://doi.org/10.1016/i.celrep.2019.08.084 PMID: 31577953

24. Krasinskas AM. EGFR Signaling in Colorectal Carcinoma. Patholog Res Int. 2011; 2011:932932. https://doi.org/10.4061/2011/932932 PMID:21403829

25. Inamura K. Colorectal Cancers: An Update on Their Molecular Pathology. Cancers (Basel). 2018; 10:26. https://doi.org/10.3390/cancers10010026 PMID:29361689

26. Markman B, Javier Ramos F, Capdevila J, Tabernero J. EGFR and KRAS in colorectal cancer. Adv Clin Chem. 2010; 51:71-119. https://doi.org/10.1016/s0065-2423(10)51004-7 PMID:20857619

27. McKay JA, Murray L, Curran S, Ross VG, Clark C, Murray GI, Cassidy J, McLeod HL. Evaluation of the epidermal growth factor receptor (EGFR) in colorectal tumours and lymph node metastases. Eur J Cancer. 2002; 38:2258-64. https://doi.org/10.1016/s0959-8049(02)00234-4 PMID:12441262

28. Resnick MB, Routhier J, Konkin T, Sabo E, Pricolo VE. Epidermal growth factor receptor, c-MET, betacatenin, and p53 expression as prognostic indicators in stage II colon cancer: a tissue microarray study. Clin Cancer Res. 2004; 10:3069-75. https://doi.org/10.1158/1078-0432.ccr-03-0462 PMID:15131045

29. Goldstein NS, Armin M. Epidermal growth factor receptor immunohistochemical reactivity in patients with American Joint Committee on Cancer Stage IV colon adenocarcinoma: implications for a standardized scoring system. Cancer. 2001; 92:133146.

https://doi.org/10.1002/10970142(20010901)92:5<1331::aid-cncr1455>3.0.co;2-m PMID: 11571750

30. Spano JP, Fagard R, Soria JC, Rixe O, Khayat D, Milano G. Epidermal growth factor receptor signaling in colorectal cancer: preclinical data and therapeutic perspectives. Ann Oncol. 2005; 16:189-94.

https://doi.org/10.1093/annonc/mdi057 PMID: 15668269

31. Tong WM, Ellinger A, Sheinin Y, Cross HS. Epidermal growth factor receptor expression in primary cultured human colorectal carcinoma cells. Br J Cancer. 1998; 77:1792-8.

https://doi.org/10.1038/bjc.1998.298

PMID:9667648

32. Markstein M, Dettorre $S$, Cho J, Neumüller RA, CraigMüller $S$, Perrimon N. Systematic screen of chemotherapeutics in Drosophila stem cell tumors. Proc Natl Acad Sci U S A. 2014; 111:4530-5. https://doi.org/10.1073/pnas.1401160111 PMID:24616500

33. Bangi $E$, Ang C, Smibert $P$, Uzilov AV, Teague AG, Antipin Y, Chen R, Hecht C, Gruszczynski N, Yon WJ, Malyshev D, Laspina D, Selkridge I, et al. A personalized platform identifies trametinib plus zoledronate for a patient with KRAS-mutant metastatic colorectal cancer. Sci Adv. 2019; 5:eaav6528.

https://doi.org/10.1126/sciadv.aav6528

PMID:31131321

34. Bangi E, Murgia C, Teague AG, Sansom OJ, Cagan RL. Functional exploration of colorectal cancer genomes using Drosophila. Nat Commun. 2016; 7:13615. https://doi.org/10.1038/ncomms13615 PMID:27897178

35. Saavedra P, Perrimon N. Drosophila as a Model for Tumor-Induced Organ Wasting. Adv Exp Med Biol. 2019; 1167:191-205. https://doi.org/10.1007/978-3-030-23629-8 11 PMID:31520356

36. Brand AH, Perrimon N. Targeted gene expression as a means of altering cell fates and generating dominant phenotypes. Development. 1993; 118:401-15. PMID:ㄹ223268 
37. McGuire SE, Mao Z, Davis RL. Spatiotemporal gene expression targeting with the TARGET and geneswitch systems in Drosophila. Sci STKE. 2004; 2004:pl6.

https://doi.org/10.1126/stke.2202004pl6

PMID:14970377

38. Nakagawa $S$, Lagisz $M$, Hector $K L$, Spencer HG. Comparative and meta-analytic insights into life extension via dietary restriction. Aging Cell. 2012; 11:401-9.

https://doi.org/10.1111/j.1474-9726.2012.00798.x PMID:22268691

39. Haselton A, Sharmin E, Schrader J, Sah M, Poon P, Fridell YW. Partial ablation of adult Drosophila insulin-producing neurons modulates glucose homeostasis and extends life span without insulin resistance. Cell Cycle. 2010; 9:3063-71.

https://doi.org/10.4161/cc.9.15.12458

PMID:20699643

40. Piper MDW, Soultoukis GA, Blanc E, Mesaros A, Herbert SL, Juricic $P$, He $X$, Atanassov I, Salmonowicz H, Yang M, Simpson SJ, Ribeiro C, Partridge L. Matching Dietary Amino Acid Balance to the In SilicoTranslated Exome Optimizes Growth and Reproduction without Cost to Lifespan. Cell Metab. 2017; 25:1206.

https://doi.org/10.1016/i.cmet.2017.04.020 PMID:28467937

41. Bossen J, Uliczka K, Steen L, Pfefferkorn R, Mai MM, Burkhardt L, Spohn M, Bruchhaus I, Fink C, Heine $H$, Roeder T. An EGFR-Induced Drosophila Lung Tumor Model Identifies Alternative Combination Treatments. Mol Cancer Ther. 2019; 18:1659-68. https://doi.org/10.1158/1535-7163.MCT-19-0168 PMID: $\underline{31217165}$

42. Antonello ZA, Reiff T, Ballesta-Illan E, Dominguez M. Robust intestinal homeostasis relies on cellular plasticity in enteroblasts mediated by miR-8-Escargot switch. EMBO J. 2015; 34:2025-41.

https://doi.org/10.15252/embj.201591517 PMID:26077448

43. Fine EJ, Segal-Isaacson CJ, Feinman RD, Herszkopf $S$, Romano MC, Tomuta N, Bontempo AF, Negassa A, Sparano JA. Targeting insulin inhibition as a metabolic therapy in advanced cancer: a pilot safety and feasibility dietary trial in 10 patients. Nutrition. 2012; 28:1028-35.

https://doi.org/10.1016/j.nut.2012.05.001 PMID:22840388

44. Fontana L, Klein S, Holloszy JO. Long-term lowprotein, low-calorie diet and endurance exercise modulate metabolic factors associated with cancer risk. Am J Clin Nutr. 2006; 84:1456-62. https://doi.org/10.1093/ajen/84.6.1456

PMID:17158430

45. Fontana L, Weiss EP, Villareal DT, Klein S, Holloszy JO. Long-term effects of calorie or protein restriction on serum IGF-1 and IGFBP-3 concentration in humans. Aging Cell. 2008; 7:681-7. https://doi.org/10.1111/i.1474-9726.2008.00417.x PMID:18843793

46. Lee C, Safdie FM, Raffaghello L, Wei M, Madia F, Parrella E, Hwang D, Cohen P, Bianchi G, Longo VD. Reduced levels of IGF-I mediate differential protection of normal and cancer cells in response to fasting and improve chemotherapeutic index. Cancer Res. 2010; 70:1564-72.

https://doi.org/10.1158/0008-5472.CAN-09-3228 PMID:20145127

47. Krittika S, Yadav P. An overview of two decades of diet restriction studies using Drosophila. Biogerontology. 2019; 20:723-40. https://doi.org/10.1007/s10522-019-09827-0 PMID:31375967

48. Romey-Glüsing R, Li Y, Hoffmann J, von Frieling J, Knop M, Pfefferkorn R, Bruchhaus I, Fink C, Roeder T. Nutritional regimens with periodically recurring phases of dietary restriction extend lifespan in Drosophila. FASEB J. 2018; 32:1993-2003. https://doi.org/10.1096/fj.201700934R PMID:29196499

49. Orillion A, Damayanti NP, Shen L, Adelaiye-Ogala R, Affronti $H$, Elbanna $M$, Chintala S, Ciesielski $M$, Fontana L, Kao C, Elzey BD, Ratliff TL, Nelson DE, et al. Dietary Protein Restriction Reprograms TumorAssociated Macrophages and Enhances Immunotherapy. Clin Cancer Res. 2018; 24:6383-95. https://doi.org/10.1158/1078-0432.CCR-18-0980 PMID: 30190370

50. Eitan E, Tosti V, Suire CN, Cava E, Berkowitz S, Bertozzi B, Raefsky SM, Veronese N, Spangler R, Spelta F, Mustapic M, Kapogiannis D, Mattson MP, Fontana $\mathrm{L}$. In a randomized trial in prostate cancer patients, dietary protein restriction modifies markers of leptin and insulin signaling in plasma extracellular vesicles. Aging Cell. 2017; 16:1430-3.

https://doi.org/10.1111/acel.12657

PMID:28921841

51. Gao X, Sanderson SM, Dai Z, Reid MA, Cooper DE, Lu M, Richie JP Jr, Ciccarella A, Calcagnotto A, Mikhael PG, Mentch SJ, Liu J, Ables G, et al. Dietary methionine influences therapy in mouse cancer models and alters human metabolism. Nature. 2019; 572:397-401.

https://doi.org/10.1038/s41586-019-1437-3

PMID:31367041 
52. Hens JR, Sinha I, Perodin F, Cooper T, Sinha R, Plummer J, Perrone CE, Orentreich D. Methioninerestricted diet inhibits growth of MCF10AT1-derived mammary tumors by increasing cell cycle inhibitors in athymic nude mice. BMC Cancer. 2016; 16:349.

https://doi.org/10.1186/s12885-016-2367-1 PMID:27255182

53. Thivat $E$, Farges $M C$, Bacin F, D'Incan M, MouretReynier MA, Cellarier E, Madelmont JC, Vasson MP, Chollet P, Durando X. Phase II trial of the association of a methionine-free diet with cystemustine therapy in melanoma and glioma. Anticancer Res. 2009; 29:5235-40.

PMID:20044642

54. Durando X, Farges MC, Buc E, Abrial C, PetorinLesens C, Gillet B, Vasson MP, Pezet D, Chollet P, Thivat $E$. Dietary methionine restriction with FOLFOX regimen as first line therapy of metastatic colorectal cancer: a feasibility study. Oncology. 2010; 78:205-09.

https://doi.org/10.1159/000313700

PMID:20424491

55. Brückl W, Tufman A, Huber RM. Advanced non-small cell lung cancer (NSCLC) with activating EGFR mutations: first-line treatment with afatinib and other EGFR TKIs. Expert Rev Anticancer Ther. 2017; 17:143-55.

https://doi.org/10.1080/14737140.2017.1266265 PMID:27898252

56. Xie YH, Chen YX, Fang JY. Comprehensive review of targeted therapy for colorectal cancer. Signal Transduct Target Ther. 2020; 5:22.

https://doi.org/10.1038/s41392-020-0116-z PMID: 32296018

57. Goseki N, Yamazaki S, Shimojyu K, Kando F, Maruyama $M$, Endo $M$, Koike $M$, Takahashi $H$. Synergistic effect of methionine-depleting total parenteral nutrition with 5-fluorouracil on human gastric cancer: a randomized, prospective clinical trial. Jpn J Cancer Res. 1995; 86:484-89.

https://doi.org/10.1111/i.1349-7006.1995.tb03082.x PMID:

58. Qi HW, Shen Z, Fan LH. Combined inhibition of insulin-like growth factor-1 receptor enhances the effects of gefitinib in a human non-small cell lung cancer resistant cell line. Exp Ther Med. 2011; 2:1091-95.

https://doi.org/10.3892/etm.2011.324

PMID:22977626

59. Ramalingam SS, Spigel $D R$, Chen $D$, Steins $M B$, Engelman JA, Schneider CP, Novello S, Eberhardt WE, Crino L, Habben K, Liu L, Jänne PA, Brownstein CM, Reck M. Randomized phase II study of erlotinib in combination with placebo or R1507, a monoclonal antibody to insulin-like growth factor-1 receptor, for advanced-stage non-small-cell lung cancer. J Clin Oncol. 2011; 29:4574-80.

https://doi.org/10.1200/JCO.2011.36.6799

PMID:22025157

60. Wang R, Yamada T, Kita K, Taniguchi H, Arai S, Fukuda $K$, Terashima $M$, Ishimura A, Nishiyama A, Tanimoto A, Takeuchi S, Ohtsubo K, Yamashita K, et al. Transient IGF-1R inhibition combined with osimertinib eradicates AXL-low expressing EGFR mutated lung cancer. Nat Commun. 2020; 11:4607.

https://doi.org/10.1038/s41467-020-18442-4 PMID:32929081

61. Raffaghello L, Lee C, Safdie FM, Wei M, Madia F, Bianchi G, Longo VD. Starvation-dependent differential stress resistance protects normal but not cancer cells against high-dose chemotherapy. Proc Natl Acad Sci U S A. 2008; 105:8215-20.

https://doi.org/10.1073/pnas.0708100105 PMID: 18378900

62. Safdie FM, Dorff T, Quinn D, Fontana L, Wei M, Lee C, Cohen $P$, Longo VD. Fasting and cancer treatment in humans: A case series report. Aging (Albany NY). 2009; 1:988-1007.

https://doi.org/10.18632/aging.100114 PMID:20157582

63. Tinkum KL, Stemler KM, White LS, Loza AJ, Jeter-Jones S, Michalski BM, Kuzmicki C, Pless R, Stappenbeck TS, Piwnica-Worms D, Piwnica-Worms H. Fasting protects mice from lethal DNA damage by promoting small intestinal epithelial stem cell survival. Proc Natl Acad Sci U S A. 2015; 112:E7148-54.

https://doi.org/10.1073/pnas.1509249112 PMID:26644583

64. de Groot S, Vreeswijk MP, Welters MJ, Gravesteijn G, Boei JJ, Jochems A, Houtsma D, Putter $H$, van der Hoeven JJ, Nortier JW, Pijl H, Kroep JR. The effects of short-term fasting on tolerance to (neo) adjuvant chemotherapy in HER2-negative breast cancer patients: a randomized pilot study. BMC Cancer. 2015; 15:652.

https://doi.org/10.1186/s12885-015-1663-5 PMID:26438237

65. Dorff TB, Groshen S, Garcia A, Shah M, Tsao-Wei D, Pham H, Cheng CW, Brandhorst S, Cohen P, Wei M, Longo V, Quinn DI. Safety and feasibility of fasting in combination with platinum-based chemotherapy. BMC Cancer. 2016; 16:360.

https://doi.org/10.1186/s12885-016-2370-6 PMID:27282289

66. Bauersfeld SP, Kessler CS, Wischnewsky M, Jaensch A, Steckhan N, Stange R, Kunz B, Brückner B, Sehouli J, 
Michalsen A. The effects of short-term fasting on quality of life and tolerance to chemotherapy in patients with breast and ovarian cancer: a randomized cross-over pilot study. BMC Cancer. 2018; 18:476.

https://doi.org/10.1186/s12885-018-4353-2

PMID:29699509

67. Safdie F, Brandhorst S, Wei M, Wang W, Lee C, Hwang S, Conti PS, Chen TC, Longo VD. Fasting enhances the response of glioma to chemo- and radiotherapy. PLoS One. 2012; 7:e44603.

https://doi.org/10.1371/journal.pone.0044603 PMID:22984531

68. Lee C, Raffaghello L, Brandhorst S, Safdie FM, Bianchi G, Martin-Montalvo A, Pistoia V, Wei M, Hwang S, Merlino A, Emionite L, de Cabo R, Longo VD. Fasting cycles retard growth of tumors and sensitize a range of cancer cell types to chemotherapy. Sci Transl Med. 2012; 4:124ra27.

https://doi.org/10.1126/scitranslmed.3003293

PMID:22323820
69. Bianchi G, Martella R, Ravera S, Marini C, Capitanio S, Orengo A, Emionite L, Lavarello C, Amaro A, Petretto A, Pfeffer U, Sambuceti G, Pistoia $V$, et al. Fasting induces anti-Warburg effect that increases respiration but reduces ATP-synthesis to promote apoptosis in colon cancer models. Oncotarget. 2015; 6:11806-19.

https://doi.org/10.18632/oncotarget.3688

PMID:25909219

70. D'Aronzo M, Vinciguerra M, Mazza T, Panebianco C, Saracino C, Pereira SP, Graziano P, Pazienza V. Fasting cycles potentiate the efficacy of gemcitabine treatment in in vitro and in vivo pancreatic cancer models. Oncotarget. 2015; 6:18545-57.

https://doi.org/10.18632/oncotarget.4186

PMID:26176887

71. Hildebrandt A, Bickmeyer I, Kühnlein RP. Reliable Drosophila body fat quantification by a coupled colorimetric assay. PLoS One. 2011; 6:e23796. https://doi.org/10.1371/journal.pone.0023796 PMID:21931614 


\section{SUPPLEMENTARY MATERIALS}

\section{Supplementary Figures}
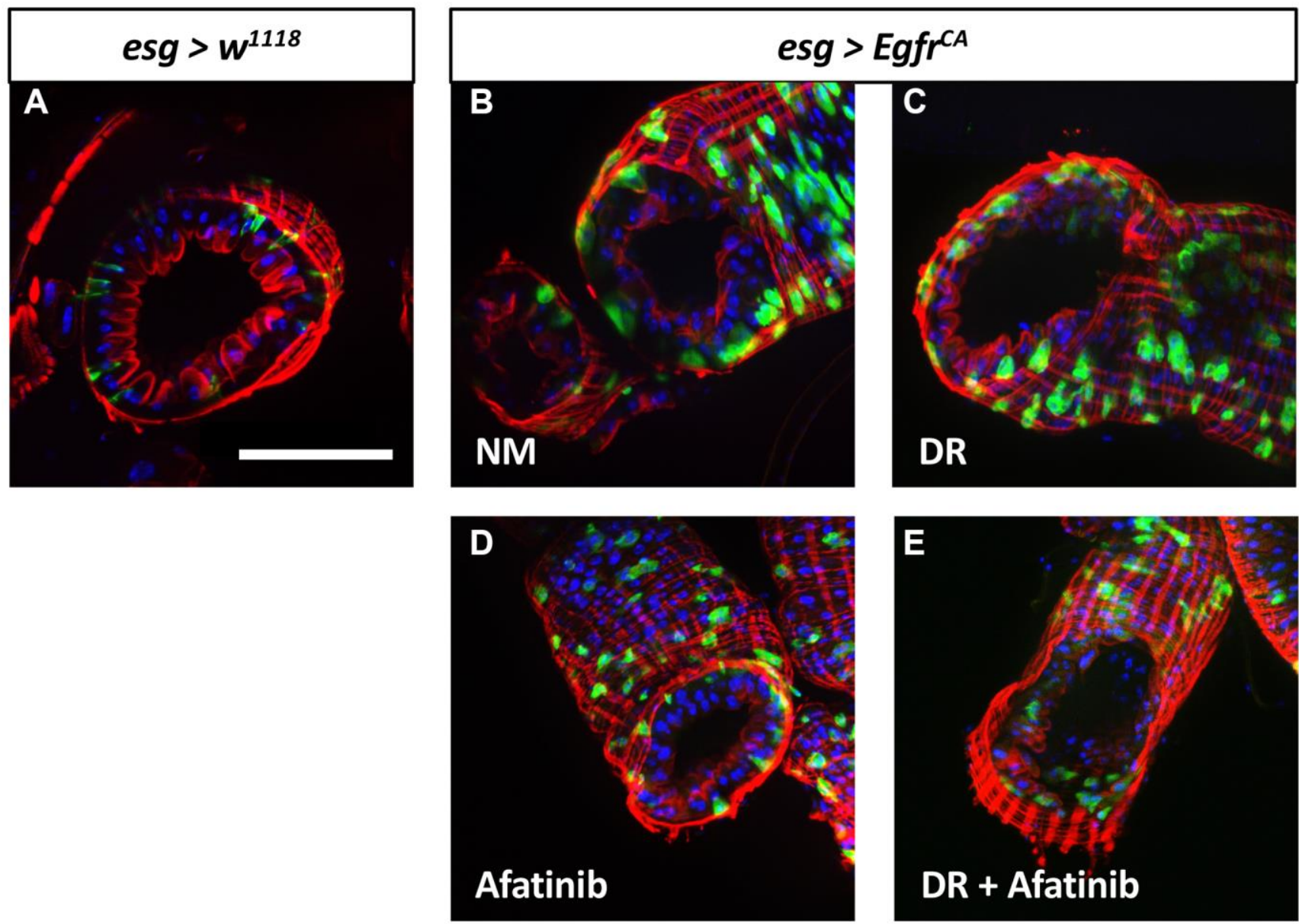

Supplementary Figure 1. Transverse sections through Drosophila abdomen of controls (esg $\left.>w^{1118}\right)$ and Egfr ${ }^{C A}(e s g>$ Egfr ${ }^{C A}$ ) after 5 days of induction at $29^{\circ}$ C. (A) Control animals on NM. (B) Egfr ${ }^{C A}$ animals on NM, (C) DR, (D) $100 \mu M$ Afatinib or (E) DR $+100 \mu \mathrm{M}$ afatinib. Abbreviations: NM = normal medium; DR = dietary restriction; green = GFP: ISC; blue = DAPI: DNA; red = Phalloidin, actin. Scale bar $=100 \mu \mathrm{m}$. 
A

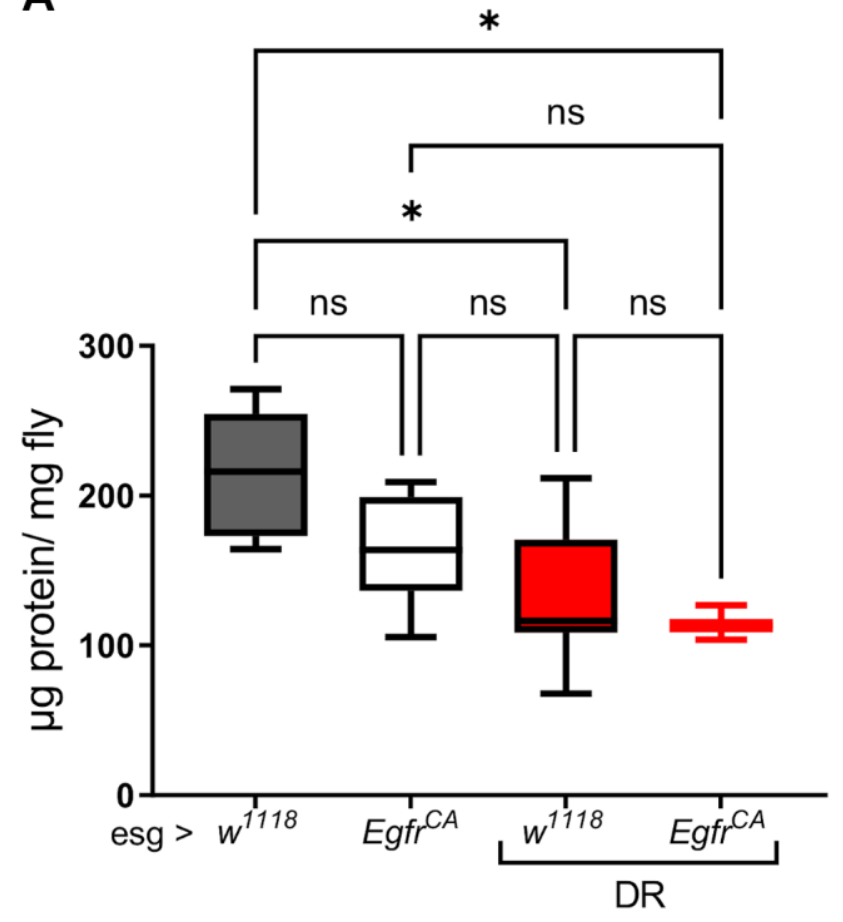

B

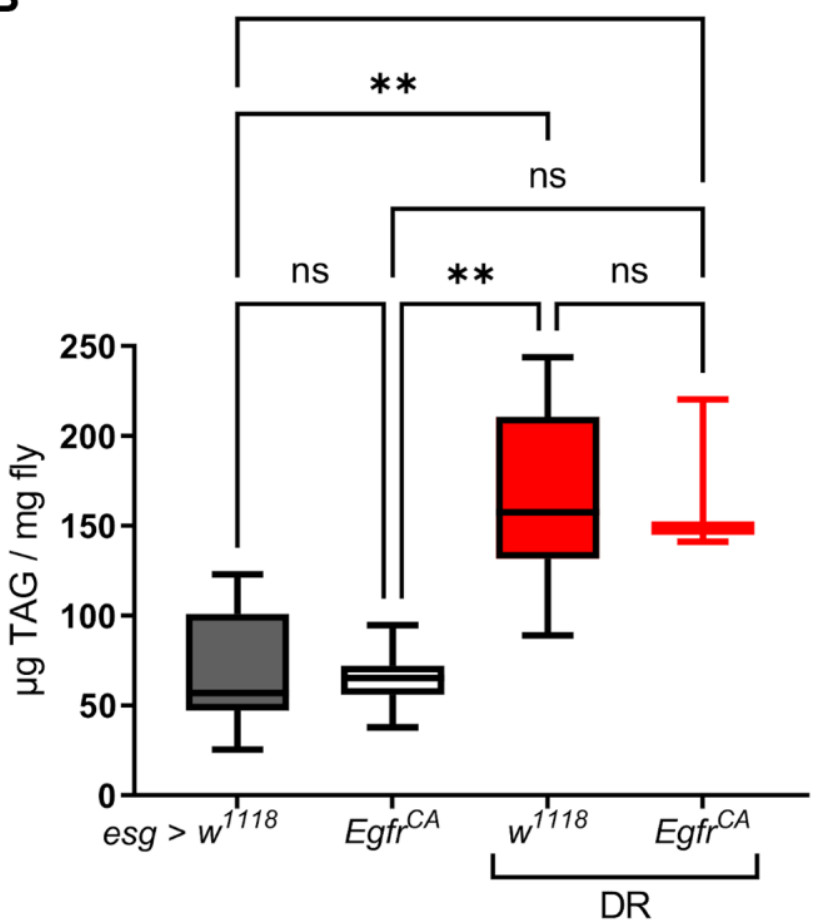

Supplementary Figure 2. (A) Protein content and (B) triacylglyceride content of controls (esg $>w^{1118}$ ) and esg $>$ Egfr ${ }^{C A}$ after 15 days of induction. Abbreviation: $D R=$ dietary restriction. Significances were calculated with ANOVA and Tukey test and are marked with lines. ns $=$ not significant, ${ }^{*}=p<0.05,{ }^{* *}=p<0.01,{ }^{* * *}=p<0.001,{ }^{* * * *}=p<0.0001 . n=3-11$.

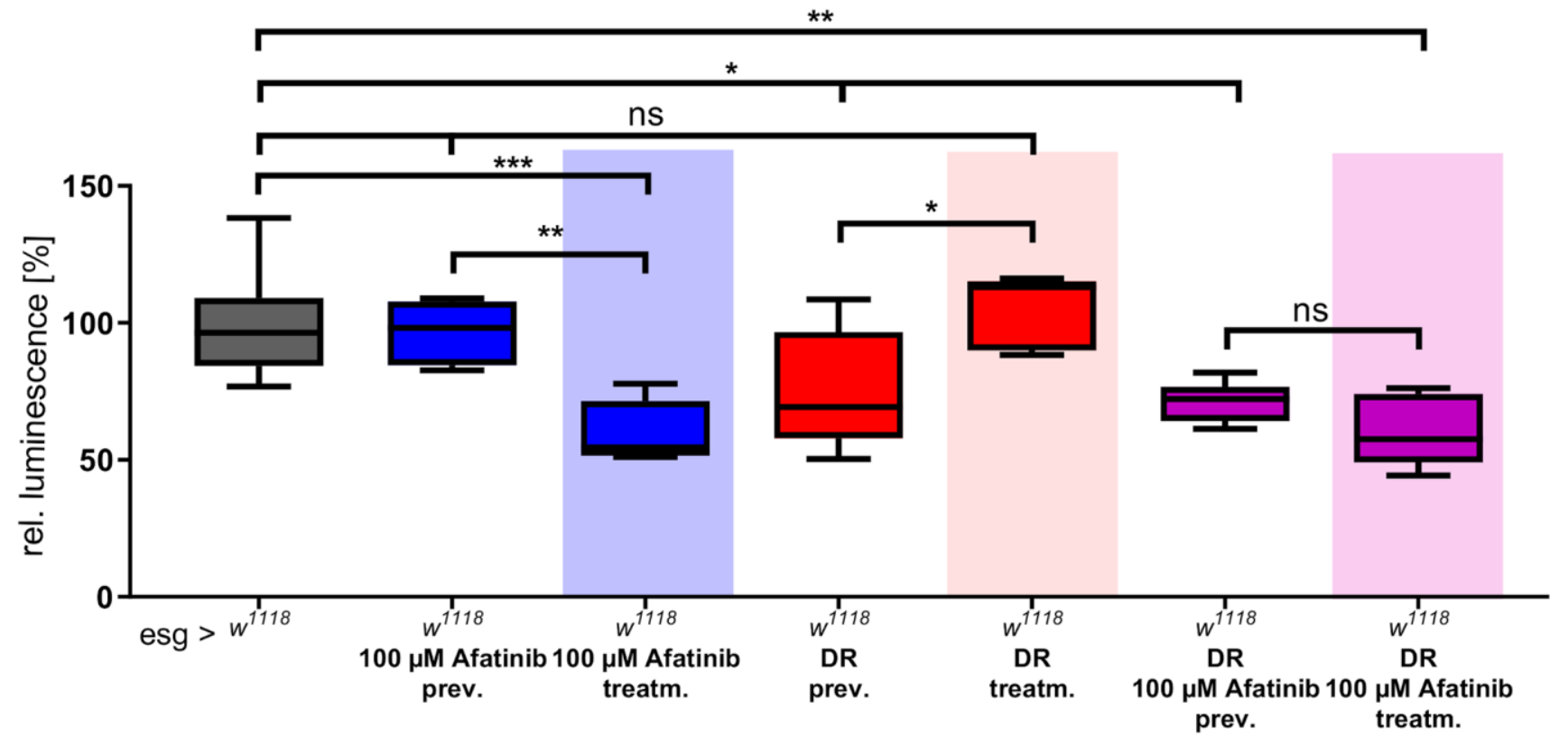

Supplementary Figure 3. Relative luminescence of $e s g>w^{1118}$ animals after 15 days of induction at $29^{\circ} \mathrm{C}$ exposed to dietary restriction and afatinib. Abbreviations: $D R=$ dietary restriction, prev. $=$ prevention Significances were calculated with one-way ANOVA and Tukey test and are marked with lines. $\mathrm{ns}=$ not significant, ${ }^{*}=p<0.05,{ }^{* *}=p<0.01,{ }^{* * *}=p<0.001,{ }^{* * * *}=p<0.0001 . n=5-8$. 